This document is the accepted manuscript version of the following article:

Mattmann, M., Logar, I., \& Brouwer, R. (2016). Wind power externalities: a metaanalysis. Ecological Economics, 127, 23-36.

https://doi.org/10.1016/j.ecolecon.2016.04.005

This manuscript version is made available under the CC-BY-NC-ND 4.0

license http://creativecommons.org/1icenses/by-nc-nd/4.0/

\title{
Wind Power Externalities: A Meta-Analysis
}

Matteo Mattmann ${ }^{1,2 *}$, Ivana Logar ${ }^{1}$, Roy Brouwer ${ }^{3,1}$

${ }^{1}$ Eawag, Swiss Federal Institute of Aquatic Science and Technology, Dübendorf, Switzerland

${ }^{2}$ Department of Environmental Economics, Institute of Environmental Studies, VU University Amsterdam, The Netherlands

${ }^{3}$ The Water Institute, Department of Economics, University of Waterloo, Canada

*Corresponding author. E-mail address: matteo.mattmann@eawag.ch 


\begin{abstract}
This study presents the first quantitative meta-analysis of the non-market valuation literature on the external effects associated with wind power production. A dataset of 60 observations drawn from 32 studies is constructed. The relative economic values of different types of externalities as well as the impact of various methodological and sample characteristics on welfare estimates are examined. The results indicate a significant effect of visual externalities on welfare estimates in both directions, i.e. a positive effect of visual improvements and a negative effect of deteriorations. This finding corresponds to predictions of the importance of visual impacts in the social science literature. External effects of wind power on biodiversity (mainly birds) do not affect welfare estimates. Indirect externalities caused by conventional sources of electricity that can be avoided by wind power, such as a the reduction of air pollution, do neither have a significant impact on welfare measures. Methodologically, we find substantial but inelastic income effects, and for choice experiments clear evidence of sensitivity to scope. From a policy point of view, our results suggest that a policy mix combining a promotion of wind turbines with another green policy facilitates expansion of wind energy.
\end{abstract}

\title{
Keywords
}

Wind power, renewable energy, externalities, non-market valuation, meta-regression 


\section{Introduction}

There is a growing consensus on the need to decarbonize the world economy (Fay et al., 2015; $\mathrm{G} 7,2015)$. This is reflected in most industrialized economies emitting less $\mathrm{CO}_{2}$ than five or ten years ago (PBL, 2014). The process of decarbonization has a profound impact on the electricity production sector. Conventional carbon-intense electricity production technologies are replaced with renewable sources of electricity in many developed countries (see e.g., ECN (2011) for an overview of renewable energy expansion projections for the EU-27). In Europe, some signs can be found of a similar replacement process that takes place for nuclear power, where Germany and Switzerland both decided to phase-out nuclear power following the 2011 nuclear accident in Fukushima, Japan. This development is restricted to Europe so far. However, with the exception of China, the often heralded "renaissance of nuclear power" does not seem to manifest itself in other parts of the world either (Mez, 2012).

Among the various available renewable sources of energy, wind power is the second most important one after hydroelectricity as measured by its share in global renewable electricity generation. In 2012, wind power had a worldwide market share of 11\% (EIA, 2012). Roughly 40\% of worldwide wind energy is produced within the EU-27, where wind power has a share in renewable electricity production of 27.1\% (EIA, 2012). Wind power has seen high and continuous growth rates that are likely to continue. The worldwide installed capacity in 2012 was roughly nine times as high as it was in 2002 with an average yearly growth rate of 25.2\% (GWEC, 2012). Predictions for future capacity growth seem equally promising. The European Wind Energy Association predicts an increase of 64\% in installed wind capacity in Europe between 2013 and 2020 (EWEA, 2014). China's roadmap foresees an even more extensive expansion in order to reach its goal of supplying $17 \%$ of electricity demand by wind power by 2050 . Achieving this goal requires the installed capacity to expand by a factor 25 and an investment of USD 2'000 billion (IEA, 2011).

Although there is an evident benefit of wind power production in terms of low greenhouse gas emissions, there are also negative effects associated with it. These effects are in general caused by renewable energy sources operating with lower energy densities than non-renewable energy carriers, which results in spatially larger production facilities (Wüstenhagen et al., 2007). This characteristic is often at the core of the observed limited community acceptance of renewable sources of energy. Wind power specifically results in a variety of uncompensated side-effects. 
Such externalities include visual impacts (e.g., Pasqualetti et al., 2002), noise pollution (e.g., Harrison, 2011) and negative effects on animals, in particular birds (e.g., Drewitt and Langston, 2006; Leung and Yang, 2012; Mathew, 2006). Offshore wind farms may have additional negative effects on marine animals caused by underwater noise (e.g., Bergström et al., 2014; Wahlberg and Westerberg, 2005) and electromagnetic fields (e.g., Gill et al., 2012; Ohman et al., 2007; Petersen and Maim, 2006). They also provide positive externalities, such as creating new habitats and recreational benefits by serving as artificial reefs (e.g., Petersen and Malm, 2006; Westerberg et al., 2013; Wilson and Elliott, 2009) and improving fishery management by facilitating the control of fish harvest surrounding wind turbines (e.g., Fayram and de Risi, 2007). Except for these direct external effects of wind power facilities there are also indirect effects, which refer to the negative effects caused by conventional energy sources that are mitigated or avoided by wind power. Such indirect effects include the avoidance of greenhouse gas emissions - although there are some emissions during construction and decommissioning of wind power plants (Weisser, 2007) - and the reduction or elimination of risks associated with nuclear power.

Apart from the valuation studies that are analyzed in this paper, there exists a number of empirical non-economic social science studies that investigate the impact of wind power characteristics on its public acceptance. These latter studies also provide an indication of relevant factors that influence public preferences and economic values of wind power externalities. They focus predominantly on visual impacts, noise and effects on birds caused by wind power turbines and link these effects to the acceptance of wind energy. A consistent result reported in this literature is the identification of visual impacts as a key externality determining public acceptance of wind power. Devine-Wright (2005) for example conclude in a literature review that negative visual impacts on the landscape and noise are the most frequent reasons for the public to oppose wind power development. Similar evidence is provided by Wolsink (2000, 2007) and Warren et al. (2005). Wolsink (2000) also identifies noise pollution and dangers to birds as important predictors of public attitudes towards wind power. However, their impact is much smaller than the impact caused by visual effects. Johansson and Laike (2007) specifically focus on the determinants of individuals to oppose local wind turbines. Their results support the importance of aesthetic effects and the "perceived unity of the environment" on local opposition. As commented by Pasqualetti (2011), there are few other artifacts that change landscapes as profoundly as wind turbines. Pedersen and Larsman (2008), Pedersen and Persson Waye (2007) and Pedersen (2011) 
study individuals' perception of wind turbines from a medical perspective and conclude that visual and audio effects have a significant impact on annoyance levels. They also find that the annoyance levels due to noise increase with visual annoyance.

This paper synthesizes the empirical evidence on the economic non-market valuation of the external effects of wind power in a meta-analysis. This is to our knowledge the first meta-analysis on the economic valuation of wind power externalities. Meta-analysis is a technique frequently used in environmental and resource economics (Nelson and Kennedy, 2008; van den Bergh et al., 1997). The usual procedure for conducting a meta-analysis in a non-market valuation context is to regress economic values (e.g. willingness to pay (WTP)) on regressors that are expected to explain data heterogeneity of economic values within- and between-studies. There are several possible objectives of a meta-analysis such as providing combined estimates of the dependent variable, explaining the variation of economic values within- or between-studies and estimating within-sample and out-of-sample predictions based on specific conditions (Nelson and Kennedy, 2008). This last objective makes meta-analysis a valuable tool in benefit-transfer applications since it allows the construction of a value function than can be used to transform values from one site to another (Bergstrom and Taylor, 2006; Brouwer, 2000).

The purpose of the meta-analysis conducted in this study is to review the existing literature and explain the observed variation in the non-market values of various types of wind power externalities whilst controlling for key methodological and sample characteristics. The main objectives are thereby to identify, disentangle and classify the external effects of wind power production valued in the literature. In a further step, welfare estimates for the non-market effects of wind power production and their drivers are quantitatively assessed in a meta-regression model. The quantitative analysis aims to answer our main research question: what is the relative importance of various external effects, methodological features and sample characteristics in explaining the economic values of wind power externalities? With respect to the types of external effects valued, the quantitative analysis distinguishes between the externalities caused by wind power directly (direct effects) and the external effects caused by other sources of electricity that are replaced by wind power (indirect effects). From a methodological perspective, this meta-analysis tests for sensitivity to scope by constructing a quantitative variable that represents the size of change valued across studies and types of externalities. 
The remainder of this paper is structured as follows. Section 2 explains the search and selection procedure of studies included in the meta-analysis. Section 3 describes the meta-regression models and the main explanatory variables. Section 4 presents the results of the meta-regression models, which is followed by discussion and conclusions in section 5 .

\section{Study selection}

The non-market valuation of wind power externalities constituted the main criterion for a study to be included in the meta-analysis. More specifically, studies that generated primary valuation data, in terms of public WTP or willingness to accept compensation (WTA), of the non-market impacts of electricity produced by wind power were considered for inclusion. We thereby included only those studies in which wind power production was identified as the source of externalities. Applying this selection criterion ensured that individuals specifically focused on wind power when valuing its external effects. Studies were included that value externalities of wind power exclusively (roughly half of all observations in the meta-analysis) and studies which value external effects of renewable energy in general but explicitly mention wind power as one of them. Some studies valued external effects directly, whereas others focused on the WTP for electricity generated by wind power compared to the electricity generated from other sources. Based on Lancaster's theory of demand (Lancaster, 1966), the latter approach usually explicitly defines the positive and negative externalities of wind power in order to elicit the economic values of the external effects of wind power more so than of its standard market good (electricity). This approach ensures that survey respondents focus on the externalities of wind power production when valuing a certain scenario. The economic values elicited in these studies are therefore comparable to the values obtained by studies valuing wind power externalities directly.

A total of 32 studies were identified. Two reports that satisfied the criteria above could not be obtained despite an extensive search procedure (in addition to being written in Nordic languages). Other studies that were excluded to avoid double counting analyzed data that had already been used in one or more other relevant publication. Six papers valued the effects of wind power without clearly defining the specific effects of wind power and thus the economic values could not be ascribed to wind electricity production. Furthermore, only two studies elicited WTA compensation (du Preez et al., 2012; Groothuis et al., 2008) and six studies provided only marginal welfare estimates elicited by choice experiments (CE) that are not directly comparable with the values obtained from contingent valuation studies (CV) (Aravena et al., 2014; Dimitropoulos and 
Kontoleon, 2009; Ek, 2006; Meyerhoff et al., 2010; Roe et al., 2001; Strazzera et al., 2012). We excluded all WTA values from the analysis. For the case of CE we only used values of policy scenarios, i.e. values that control for the level of changes in attributes. These values are better comparable to values obtained by $\mathrm{CV}$ studies than marginal estimates valuing marginal changes in an attribute without considering the scope of change. Including WTA values and marginal values of CE in the meta-analysis would have expanded the number of observations but at the same time increase the heterogeneity in the dataset, which would require additional control variables and reduce degrees of freedom. Being forced to choose, we decided to opt for higher comparability of the monetary values and increased data homogeneity.

The search procedure was conducted in the first half of 2015. Online databases that were browsed included Google Scholar, Scopus, Econlit and RePEc. ProQuest was used to search specifically for relevant $\mathrm{PhD}$ theses. The search included published papers as well as working papers, conference papers, PhD theses, Master theses, government and non-government reports. The main keywords that were used in the search process included the following terms and combinations thereof: wind power, valuation, WTP, WTA, stated preferences, revealed preferences, contingent valuation, choice experiment and externalities.

Table 1 provides the list of studies included in the database collected by the search and selection procedure described above. Most of the studies obtained are articles published in international peer-reviewed journals, but the database also includes one $\mathrm{PhD}$ thesis, one conference paper and one working paper. All of them elicit economic values by stated preference methods (either CV or CE). There are hence no observations based on revealed preferences in the dataset. The studies cover a time period of 15 years, between 1998 and 2012. Peer-reviewed papers included in the analysis received on average 68 citations (median of 29) measured by the Google Scholar citation index, with one study having a maximum of 267 citations (until July 2015).

\section{[TABLE 1 AROUND HERE]}

\section{Methodology}

In this study, meta-regression models are applied to analyze the impact of the valuation object, study and sample population characteristics on stated preferences related to wind power. Metaregression models mainly differ by how they treat data heterogeneity, heteroscedasticity of effectsize variances and non-independence of observations obtained from the same studies (Nelson and 
Kennedy, 2008). Section 3.1 explains these issues and how they are addressed in this study. Section 3.2 introduces the explanatory variables included in the meta-regression models.

\subsection{Meta-regression models}

Meta-analyses study data obtained from different papers, authors and countries. This implies that the effect-size examined (i.e. the dependent variable) may not measure the exact same concept in all the studies included in the analysis (Smith and Pattanayak, 2002). Furthermore, the data elicited from surveys stems from samples that differ in individual-specific aspects and other design elements (Ringquist, 2013). In a meta-analysis it is therefore crucial to define the examined effect-size as precisely as possible, to include as many covariates as feasible and to improve comparability by adjusting the data and dropping observations that lack comparability (Nelson and Kennedy, 2008; Smith and Pattanayak, 2002). The covariates included in this analysis control for differences in the types of wind power externalities valued as well as for variations in methodological and sample characteristics.

A further consequence of combining multiple studies in a meta-analysis is that the values obtained from each study differ in their variances. Observations with smaller variances are generally more reliable (Nelson and Kennedy, 2008). One approach to include this information in the meta-regression is to use the inverse of the variances as weights (e.g., Lipsey and Wilson, 2001). We did not have sufficient information to follow such a procedure in our analysis. Alternatively, we controlled for quality differences between studies by using the square root of the study sample size as a weight, assuming that studies using larger sample sizes produce more precise data (e.g., Nelson and Kennedy, 2008).

Finally, non-independence of observations from the same studies is another issue in metaanalyses. This is due to the fact that single studies often produce multiple values and the observations drawn from the same study may therefore suffer from within-study correlation (Nelson and Kennedy, 2008). A remedy for within-study correlation is to include only one observation per study. This may result in a serious loss of observations and estimation leverage because many observations from the same study share common characteristics which more easily allows to identify and isolate the differences between the observations (Ringquist, 2013). An alternative solution to address non-independence is to explicitly take the hierarchical structure of 
the data into account by estimating either panel data models or more advanced mixed-effects models (Nelson and Kennedy, 2008).

We apply three different meta-regression models in order to address the econometric issues described above. Model 1 is estimated by weighted least squares. Model 2 is a random-effects panel model with individual studies defined as cross-sectional units. Model 3 is an extension of the random-effects model that allows not only intercept coefficients, but also slope parameters to be randomly distributed (Cameron and Trivedi, 2005).

The baseline model (model 1) is specified as follows (e.g., Harbord and Higgins, 2008):

$$
y_{i}=x_{i}^{\prime} \beta+\varepsilon_{i} \text { with } \varepsilon_{i} \sim\left[0, \frac{\sigma^{2}}{w_{i}}\right]
$$

where $y_{i}$ denotes the dependent variable, i.e. the welfare estimates for wind power externalities of observation $i, x_{i}$ is a vector of regressors, and $\beta$ is a vector of associated coefficients. The observations are weighted by the square root of their respective sample size in this model. For this reason analytic weights are applied which assume an error term with mean equal to zero and weighted variance of $\sigma^{2} / w_{i}$, where $\sigma^{2}$ is an unknown variance estimated in the regression and $w_{i}$ are the known weights. Variances are thus assumed to be smaller for observations that are based on a larger sample size.

The model above serves as a baseline case and is compared with more refined models that take the hierarchical data structure inherent in meta-data into account (models 2 and 3). Model 2 is based on random-effects and is estimated using a maximum likelihood estimation procedure where $y_{i j}$ is observation $i$ from study $j$ :

$$
y_{i j}=x_{i j}^{\prime} \beta+\mu_{j}+\varepsilon_{i j} \text { with } \mu_{j} \sim\left[\mu, \sigma_{\mu}^{2}\right] \text { and } \varepsilon_{i j} \sim\left[0, \sigma_{\varepsilon}^{2}\right]
$$

This model has two error terms: $\varepsilon_{i j}$ denotes the standard error term, whereas $\mu_{j}$ is a random variable that varies across $j$ studies, but is assumed to be distributed independently of the regressors (Cameron and Trivedi, 2005). Both the random-effects as well as the error term are assumed to be identically and independently distributed (iid). 
The second model incorporates systematic differences in mean welfare estimates between studies and is therefore able to reproduce the actual data structure more realistically than model 1 . An even more elaborated model would also take differences in the impact of individual regressors on the dependent variable between studies into account. Such differences can be modelled by taking not only random intercepts, but also random slope parameters into account. This results in a mixed-effects model (model 3) ${ }^{1}$, which can be described as follows (Cameron and Trivedi, 2005):

$$
y_{i j}=x_{i j}^{\prime} \beta+z_{i j}^{\prime} \mu_{j}+\varepsilon_{i j} \text { with } \varepsilon_{i j} \sim\left[0, \sigma_{\varepsilon}^{2}\right]
$$

where $x_{i j}$ denotes the regressors, $z_{i j}$ is a vector of observable characteristics and represents a subset of $x_{i j}$ that includes the variables in the random part, $\mu_{j}$ a random vector and $\varepsilon_{i j}$ is the standard error term. Mixed-effects models allow for the estimation of both fixed-effects and random-effects. Fixed-effects describe the ordinary effects of regressors on the dependent variable. Their slope and intercepts describe the impacts for the sample as a whole. These are the main effects of interest. Random-effects are the intercepts and slope parameters that vary across studies and therefore capture the heterogeneity between them. Random-effects are usually not estimated directly, but their variances are calculated instead. The size and standard errors of these variances indicate whether there exist significant variations between studies in the slope coefficients of the regressors that are assigned to the random part (Hamilton, 2012).

\subsection{Variable definition}

One of the main goals of a meta-analysis is to explain variation in effect-size estimates, that is, variation in the dependent variable of interest, here welfare estimates for externalities associated with wind power. There are different categories of explanatory variables that may have an impact on such welfare measures. Most importantly, the types of externalities valued differ between the studies in the database. Furthermore, the studies differ with respect to their methodological features as well as the characteristics of survey respondents. All of these study properties may help explaining differences between the elicited welfare measures. Sections 3.2.1 and 3.2.2 describe in

\footnotetext{
${ }^{1}$ Depending on the context of application such models are also called hierarchical, multilevel, random coefficients or variance components models.
} 
more detail the wind power externalities as well as the methodological features and characteristics of the samples used in the studies that are included in the dataset.

\subsubsection{Wind power externalities}

Table 2 identifies the types of externalities that are valued in each study included in the database (indicated by the same study-ID as in Table 1). The externalities are classified into various categories. The last column " $\mathrm{N}$ ” denotes the number of studies valuing each externality and each category (in bold). Air pollution and climate change describes the major positive indirect external effect of wind power. This category summarizes studies that estimate WTP for avoiding greenhouse gas or other emissions, for the improvement of air quality and for avoiding the environmental drawbacks of electricity produced by non-renewable sources such as coal. The independence from fossil fuels describes a further positive and indirect external effect of wind power installations. The following three categories, biodiversity, visual and noise impacts describe the main direct external effects of wind power. Effects on biodiversity can be negative or positive, depending on the framing of the scenario compared to the current situation described in the stated preference surveys. All studies framed visual and audio impacts as negative externalities caused by wind power. A couple of studies also valued institutional arrangements associated with green policy measures such as the introduction of a coherent environmental policy, the set-up of a green fund or the transfer of wind power revenues to the local municipality earmarked for nature conservation. These effects are not externalities of wind power in a strict sense but since they were valued repeatedly in various studies we decided to include them in the analysis. Finally, there are a number of factors valued by one study only. Such factors include the location of facilities, ownership structures, the amount of public consultation involved, the number of blackouts, the area of land that is affected by a facility and recreational activities associated with an artificial reef created by offshore wind power turbines.

\section{[TABLE 2 AROUND HERE]}

A frequency analysis of the number of studies that value each type of externality shows that nearly two-thirds of all papers value visual effects. Air pollution and climate change are also valued frequently, in 53\% of the studies. Only five out of the 30 studies value noise impacts and seven of them explicitly assess economic values that represent wind power effects on fauna and bird life." Therefore, as in the broader social science literature, visual impacts are identified as the most 
important external effects of wind power in the non-market valuation literature, followed by air pollution and climate change.

The externalities shown in Table 2 had to be meaningfully summarized before they could be included in the meta-analysis. Table 3 provides the resulting list of regressors describing externalities that are included in the meta-regression models. The directions of the valued external effects are also indicated, i.e. whether they measure improvements or deteriorations compared to the baseline conditions. Different directions are captured by separate dummy variables. Noise effects of wind power are not included in the meta-regression because the number of observations valuing this externality in the database is too low: there are only three studies valuing a noise deterioration and two studies valuing an improvement relative to the baseline scenario. The same holds for the valuation of independence from fossil fuels.

\section{[TABLE 3 AROUND HERE]}

\subsubsection{Methodological and sample characteristics}

Table 4 describes various methodological and sample characteristics of the studies in the dataset. With respect to the valuation methods and survey modes, most of the studies applied CEs (53\%) and conducted face-to-face surveys (38\%). Only eight out of the 32 studies defined a payment frequency other than annual or monthly. There is a low variation in the data with respect to payment vehicles and payment durations. An increase in electricity costs is the most common payment vehicle used in $78 \%$ of all studies. More than $80 \%$ of the studies defined a payment vehicle of indefinite length. Only three studies included a one-off payment frequency. The majority of the studies was carried out in Europe (63\%), followed by the United States (25\%) and Asia (9\%). The shares of wind power production by these three geographical areas in worldwide production are approximately 40\% for the EU-27, 27\% for the USA and 27\% for Asia (EIA, 2012). In terms of number of studies, these figures show that Europe is overrepresented whereas Asia is underrepresented in the dataset. However, this geographical distribution does not need to be representative of the distribution of externalities, as it might be the case that wind turbines in Asia are associated with less externalities than wind turbines in Europe. Furthermore, only one study was found for Germany and Spain, the two largest wind power producers in Europe. Some studies valued both onshore and offshore facilities, while 56\% focused exclusively on onshore wind power and $22 \%$ on offshore wind power. Considering that $98 \%$ of the installed wind power ca- 
pacity worldwide is onshore (GWEC, 2012), offshore wind power facilities are hence overrepresented in the dataset. The focus on visual effects associated with wind power (see Table 2) is in line with the fact that nearly half of all studies use visualizations in their surveys to represent these visual impacts.

\section{[TABLE 4 AROUND HERE]}

The methodological and sample characteristics of the studies in the dataset had to be synthesized into a number of variables that could be included in the regression analysis. Furthermore, a few additional variables describing more general study characteristics were constructed based on external data sources (ECN, 2011; IEA, 2014a, 2014b; OECD, 2014) such as the share of wind power in national electricity production. Table 5 provides the full list of regressors included in the meta-regression models related to the methodological and sample characteristics of the data. Special care was taken in the process of selecting variables for the meta-regression to ensure that the theoretically most relevant variables are included in the models and multicollinearity is minimized.

\section{[TABLE 5 AROUND HERE]}

The size of change variable included in this study aims at capturing the scope effect. It distinguishes between small, medium and large changes valued in different studies. Classification of the size of change was done based on the baseline and alternative policy scenarios descriptions provided in the individual studies. The underlying assumption in variable construction was that the number of wind turbines associated with the valued external effects is proportional to the magnitude of change valued. The classification was done in two steps. First, each observation was assigned the number of turbines that were considered in the survey. A majority of surveys provided this information directly, some however only informed about the amount of electric power that would be produced, usually measured in megawatts (MW). For these cases the number of turbines was estimated based on the assumption that an average wind turbine generates roughly 2.5 MW of electric power. Other studies defined the magnitude of electricity generation as a change in the national share of renewable or wind energy, replacing fossil fuel with wind energy or as tons of avoided $\mathrm{CO}_{2}$ emissions. All these values were transformed into the number of turbines by using data on national shares of renewable energy or national electricity production, the amount of electricity generated by an average fossil fuel power plant and the average 
amount of $\mathrm{CO}_{2}$ emissions that is avoided by a wind turbine. Nine studies did not provide any information about the magnitude of electric power production. For these observations, the median number of turbines of all other observations in the dataset was used. In a second step, the number of turbines associated with each study was transformed into a categorical variable (small, medium, large). Small change describes the amount of electricity that corresponds to less than 50 wind turbines, medium between 50 and 300 turbines and large change is associated with more than 300 turbines. The relatively large number of turbines even in the small change category can be explained by the fact that the majority of the studies in the dataset focused on future projects, that is, on projects that are either hypothetical or in the initial planning stages and that tend to be larger than existing wind farms.

An important adjustment of the dependent variable was to express all welfare measures as an annual value to the degree that this was possible. Monthly, bi-monthly and quarterly payments were extrapolated to yearly payments. Three studies used one-off payment vehicles and hence had to be excluded from the analysis. Payment vehicles defined as an increase in electricity costs per KWh were expressed on an annual basis using the average annual KWh consumption in the country where the study was conducted (IEA, 2014a, 2014b). One study defined the payment vehicle "per trip" and the welfare estimate was adjusted by multiplying it by the average number of trips per year. Another study used a payment vehicle per trip for a sample consisting of tourists at a beach resort. Since a majority of them declared to be loyal regular visitors of this beach resort, this payment vehicle was treated as an indefinite yearly payment. Another study used a monthly payment vehicle restricted to one year and the effects occurring from the associated wind project were limited to one year as well. Assuming similar discount rates for future benefits and costs, this welfare estimate was included in the analysis without adjustment. Two studies restricted payment vehicles to 3 and 5 years. However, the empirical literature usually reports rather high individual discount factors (e.g., Harrison et al., 2000), implying that benefits and costs after a certain point in the near future are not relevant for individual decisions. We thus assumed that payment vehicles restricted to 3 or 5 years to be similar to payment vehicles of indefinite durations.

Finally, the household income of surveyed participants was made comparable across studies, just like the welfare estimates, by expressing them in 2014 USD. They were adjusted for annual consumer price inflation and GDP purchasing power parities (PPPs) of the countries where the stud- 
ies were conducted (OECD, 2014). Furthermore, gross income data was transformed into disposable income by adjusting it for tax rates at average income level in a country and for the year of survey implementation.

\section{Results}

\subsection{Descriptive statistics}

From the database with 32 studies, 52 observations from 29 studies could be used in the subsequent meta-regression. Sixteen studies contributed with a single observation. Studies provided more than one observation when using different samples of respondents (for example distinguishing between local residents, visitors and non-users of a resource) or because they valued various combinations of wind power externalities. The number of respondents underlying each observation varies considerably (from 31 to 2332), with an average of 409 respondents per observation (median of 339). About half of all observations $(\mathrm{N}=27)$ included respondents that are either local residents or visitors to the area where the externalities of wind power are valued.

Furthermore, only positive WTP values were included, implying that two negative WTP estimates had to be eliminated from the analysis. This approach ensures that the welfare measures analyzed in the meta-regression are comparable and positive, although they may value combinations of improvements and deteriorations of resources compared to the status quo. The natural logarithm of the welfare estimates proved to fit the data better than including them linearly or applying another transformation. Table 6 shows the descriptive statistics of explanatory variables considered for the meta-regression models. The summary statistics for the valued externalities are omitted because the economic values estimated often represent a combination of wind power characteristics, i.e. the externalities are rarely valued on their own.

\section{[TABLE 6 AROUND HERE]}

The dummy variables representing sensitivity to scope (i.e. the size of change) indicate that welfare estimates substantially increase when the size of change shifts from small to medium and increase slightly less for shifts from medium to large changes in externalities. This preliminary result suggests the presence of sensitivity to scope but diminishing marginal utility when moving from small to medium and then to large impacts of wind power. The results of the Kruskal-Wallis 
test confirm that there are significant differences in welfare estimates for small, medium and large changes at the $5 \%$ significance level.

The mean WTP values for different regions suggest that surveys conducted in North-America or Asia generate significantly higher welfare estimates than surveys in Europe. Furthermore, studies using the CE method elicit significantly higher economic values than CV studies. The KruskalWallis test confirms that differences in welfare estimates due to geographical location and valuation method are statistically significant at the $5 \%$ level.

Although the PPP adjusted mean welfare measures associated with offshore wind power are higher than for onshore turbines or for studies that do not discriminate between the two, the Kruskal-Wallis test statistic cannot be rejected, implying that there are no statistically significant differences between them. Finally, the Kruskal-Wallis test statistic for local residents, visitors and non-users of a resource suggests that there are no significant differences in economic values reported between these groups of respondents either. However, the results reported in Table 6 need to be interpreted with care since the standard errors are relatively high.

\subsection{Meta-regression results}

The results of the three models described in section 3.1 are presented in Table 7. All three models perform well with reasonable $\mathrm{R}^{2}$ and pseudo- $\mathrm{R}^{2}$ statistics, although the models are not directly comparable based on these indicators. Estimating three different types of models also serves as a robustness check for the stability of the results obtained. This is especially important considering the small number of observations. Most of the variance of the random terms did not turn out to be significant in the mixed-effect model 3. In other words, differences in the impact of most of the explanatory variables across studies are not significant and allocating these variables to the random-effects part of the models does not improve the model fit in most cases. This is supported by Likelihood-ratio (LR) tests. The majority of variables are consequently specified as fixed-effect terms with the exception of the dummies for local residents and improvements in air pollution and climate change. Although the variances of these terms do not reach significance either, the random specification of the terms resulted in an improved model fit. The Akaike information criterion (AIC) and the Bayesian information criterion (BIC) both show that there is an improvement when moving from model 2 to model 3. The outcome of the LR test confirms the statistical significance of this improvement. Since cross-validation of the three models shows that the pre- 
dictive errors are substantially reduced in models 2 and 3 compared with model 1 (see section 4.3), the following interpretation of the results mainly focuses on the coefficients that are stable across models 2 and 3 .

\section{[TABLE 7 AROUND HERE]}

The coefficients for variables indicating the types of externalities valued provide evidence that there is, as expected, a significant positive impact of improvements and a significant negative impact of deteriorations in visual effects caused by wind power turbines on WTP. The same holds for the implementation of a green policy. This variable has a significant positive effect on WTP even though it describes a rather heterogeneous category of externalities. In contrast, the coefficient estimates for the biodiversity variables do not reach significance level in any model, irrespective of whether improvements or deteriorations are valued.

The parameter estimates for reducing air pollution and climate change are not statistically significant in any model either. This means that avoiding air pollution and climate change, the second most frequently valued positive externality of wind power production in the dataset, does not result in significantly higher welfare estimates. Therefore, a reduction of air pollution and a mitigation of climate change do not seem to improve individuals' utility. A possible explanation for this finding is that the survey participants are not aware or do not believe that wind power reduces air pollution or climate change, possibly because of its relative small share in national energy production. In order to check for other explanations, the dummy variable for improvements in air pollution and climate change was interacted with the survey year and the share of wind power in national electricity production. Neither of these interaction terms was significant and therefore they were not included in the models presented here. Hence, there is no significant effect of a change in air pollution and climate change over time or as part of a national energy policy on welfare estimates.

Signs and statistical significance of the coefficients for dummy specifications describing a medium and a large change in externalities provide evidence that economic values are sensitive to scope. This finding is further supported by the relative magnitudes of the coefficients, which are, depending on the model, $30 \%$ to $65 \%$ higher for a large than for a medium change. This result is in line with the scope sensitivity detected in the non-market valuation literature (e.g., Bateman and Brouwer, 2006; Carson and Mitchell, 1993; Carson, 1997; Ojea and Loureiro, 2011; Smith 
and Osborne, 1996). The evidence for sensitivity to scope found in this study is however not restricted to a specific externality. This was tested by interacting the scope dummies with the types of externalities, which did not result in any significant effects. Sensitivity to scope therefore exists for all types of externalities. With respect to differences in sensitivity to scope between CV and CE valuation methods, it is theoretically expected that estimates derived from CEs are more sensitive to scope than estimates from CV studies because in CEs respondents are often asked to directly compare different provision levels of goods or services which is not always the case in CV studies (Foster and Mourato, 2003). This theoretical hypothesis is confirmed in a number of empirical studies (e.g., Foster and Mourato, 2003; Goldberg and Roosen, 2007). In order to test for such an effect we ran an additional specification of models 2 and 3, in which interaction effects between the valuation method and dummies for medium and large changes were included (see Table A1 in the Appendix). This analysis reveals that these interaction effects are statistically significant with positive signs, thereby confirming theoretical and empirical evidence that welfare estimates from CEs are more sensitive to scope than estimates from CV studies.

The coefficient estimate for offshore wind power projects indicates that offshore wind farms have a significantly negative effect on economic values compared to onshore wind farms and observations where the two categories are not distinguished explicitly. Put differently, WTP that expresses externalities of onshore wind farms is significantly higher than WTP for the avoidance or mitigation of the externalities of offshore farms This result is not driven by different sensitivities to the visual effects of onshore and offshore wind power facilities, as interaction of the dummies for visual effects with the offshore variable did not yield a significant outcome. This interaction effect is therefore omitted from the analysis. The negative coefficient for the offshore dummy is in line with the non-economic social science literature comparing the social acceptance of onshore and offshore wind energy, where people tend to prefer offshore to onshore wind farms (e.g.; Bishop and Miller, 2007; Ladenburg, 2008). However, Haggett (2011) argues that although resistance to offshore developments might be lower, this does not imply that there is no resistance and that the public opinion can be neglected in the decision-making process.

The variable controlling for the share of wind energy in total electricity production in the countries where the surveys were conducted does not yield conclusive results. This variable has a significantly negative effect on economic values in all three models if included in the models without its quadratic term (not shown in the estimated models here). In order to control for nonlinear 
relationships, a quadratic term is included in the analysis. This quadratic term is negative and significant in models 1 and 2, whereas the coefficient for the linear relationship loses its significance. This suggests an exponential relationship between WTP for mitigating or avoiding external effects and national shares of wind power. In other words, WTP decreases exponentially as the share of wind power in national energy production increases. However, a more in-depth analysis of the spatial effects of wind power would include finer grain geographical data on the distribution of wind turbines that go beyond data at the national level. Unfortunately none of the studies provided such information.

Whether nuclear power is included in the baseline scenario or not does not exert a significant influence on WTP values. This finding corresponds to the insignificance of the coefficient for air pollution and climate change, confirming that only direct effects of wind power are valued significantly whereas indirect effects, i.e. avoided effects of other sources of electricity, namely greenhouse gas emissions and nuclear risk, do not seem to have an effect on the economic values associated with wind power externalities.

As expected, the income effects are consistently positive and significant. Since both the dependent and income variables are transformed into natural logarithms, the coefficient for the income variable represents the income elasticity of WTP for external effects of wind power. The positive income elasticity is relatively high compared to other studies but below unity in all three models. Demand for the valued resources is therefore inelastic, implying that they are perceived as necessity rather than luxury goods. The literature on the income elasticity of WTP for the conservation of environmental goods supports this result. Jacobsen and Hanley (2009) for example found the income elasticity of WTP for biodiversity conservation in a meta-analysis to be higher than zero but also inelastic. The income elasticities they reported are lower than in our study. Similar evidence is found by Kristrom and Riera (1996) and Hökby and Söderqvist (2003). The latter study estimates income elasticities of WTP for a broad range of environmental resources in Sweden.

The dummy variable for visitors is positive and significant in models 2 and 3 . This indicates that survey respondents who visit the area of the planned wind power turbines are willing to pay significantly more for improvements or avoiding deteriorations caused by wind power facilities than respondents who live in the vicinity of such plants or are non-users of the resources valued. The insignificance of the variable for local residents suggests that residential proximity to future wind 
power plants has no effect on economic values. Our results thus provide no evidence for either not-in-my-backyard (NIMBY) or please-in-my-backyard (PIMBY) effects sometimes found in the literature (e.g., van der Loo, 2001; Warren et al., 2005).

\subsection{Cross-validation}

The meta-regression models presented above are based on a low number of observations and a relatively large number of regressors. This increases the risk of overfitting the models. In order to test for overfitting and compare the different models, a cross-validation procedure is applied. This procedure consists of three steps. First, a share of the total observations is randomly chosen (here 80\%) and the models are estimated based on this reduced dataset. The coefficients obtained are used in a second step to predict the values of the remaining $20 \%$ of the data. Finally, the predicted values are compared to the actual values and a standard error of prediction is calculated. After repeating this procedure 10,000 times, distributions of the standard errors of prediction are obtained. The results are shown in Figure 1.

\section{[FIGURE 1 AROUND HERE]}

The mean value of the log-transformed dependent variable equals 4.87. The mean standard error of the prediction of model 1 is 1.24 , which is reduced to 0.65 and 0.57 in models 2 and 3, respectively. The panel data specification of model 2 substantially reduces the prediction errors. Allowing between-study slopes of the regressors for improvement in air pollution and climate change and local residents to vary in model 3 results in a further reduction of the prediction errors although the difference to model 2 is small. The results of this cross-validation procedure provide evidence that models 2 and 3 perform best and model 1 worst.

What matters from a more practical perspective are the expected errors of the models when applied in a benefit transfer exercise. The relative performance of models 1,2 and 3 for such purposes is assessed by estimating the model based on $n-1$ observations and predicting the observation that is left out (e.g., Brander et al., 2013). In a next step, the actual and predicted values are compared and a percentage prediction error is calculated. After following this procedure for every observation in the dataset, the prediction error can be averaged. This error amounts on average to $21.9 \%$ for the first model, $11.2 \%$ for the second model and $10.5 \%$ for the third model (median values are $12.3 \%, 4.3 \%$ and $2.7 \%$ respectively). This implies that if model 1 was applied to another policy context and the mean value of wind power externalities was predicted based on the 
existing literature using this model specification, this would result in an error margin of $21.9 \%$. The benefit transfer errors found here are rather low compared to the magnitudes reported in the literature (e.g., Brander et al., 2006; Brander et al., 2013; Brouwer, 2000; Rosenberger and Stanley, 2006) and confirm the usefulness of meta-analysis for benefit transfer purposes. However, a careful interpretation of these results is warranted since the standard deviations of this measure of prediction are of similar magnitudes as the values themselves (results are available from the authors upon request). Furthermore, ensuring low heterogeneity of the values in the dataset used in a meta-analysis is of even higher importance if the aim is to provide values for benefit transfer purposes (Smith and Pattanayak, 2002). Although it is possible to control for data heterogeneity in a meta-regression, some authors nevertheless advise against using meta-analysis based on choice experiment values for benefit transfers (e.g., de Ayala et al., 2014).

\section{Discussion and conclusions}

This paper applies a quantitative meta-analysis to the non-market valuation literature on wind power externalities. The analysis allows to identify factors that explain study-to-study variation in welfare estimates for the non-market effects of wind power.

The results reveal that improvements as well as deteriorations of visual effects caused by wind farms are valued. The importance of visual effects for people's preferences for wind power is supported by the fact that this is the most frequently valued externality associated with wind power development. It also confirms predictions from the non-economic social science literature on the importance of visual effects of wind power for the public acceptance of this electricity source. The empirical evidence further shows that the negative effects of wind power on biodiversity do not exert a significant influence on welfare measures independently of whether improvements or deteriorations in biodiversity are valued. The variable describing the effects on biodiversity comprises effects on habitat and flora, effects on fauna and bird life and effects on biodiversity more generally (as explained in Table 2). The effects on fauna and bird life are the effects that are valued most often in seven out of the eleven studies that value biodiversity. The insignificant effects on biodiversity may therefore be interpreted as partially reflecting insignificant effects on birds. This corresponds to findings reported in Erickson et al. (2005), who put the number of birds killed by wind turbines in a broader context by comparing this with other sources of birds' death. They estimate that between 500 million and 1 billion birds are killed annually due 
to anthropogenic sources in the United States. The main causes of these deaths include collisions with buildings, power lines and cars as well as cat killings. Domestic cats alone are responsible for 100 million deaths annually, whereas wind turbines are estimated to cause roughly 30,000 deaths.

Focusing on methodological and sample characteristics, we find strong evidence for income effects and sensitivity to scope. A sensitivity analysis including interactions of the valuation method with the scope variables furthermore suggests that sensitivity to scope holds for CEs but not for CV studies. Although we find clear evidence for scope effects, it cannot be ruled out that this is an artefact of our specific definition of the scope dummies. Our scope variables rely on the assumption that the magnitude of an externality is proportional to the number of turbines causing the externality. We constructed the scope variables based on this assumption but there may be other possible definitions of scope as well. For example, the amount of electricity produced by a turbine or the height of turbines may be equally relevant for external effects than the number of turbines. Some characteristics that may be related to the observed significant scope effects, such as whether respondents are residents of the area where turbines are planned or whether externalities are caused by onshore or offshore wind parks, are controlled for in our study. Due to a lack of data, the influence of residential distance to current wind parks could not be investigated here.

The insights provided by this study are of considerable policy relevance for prospective wind power investment and expansion projects worldwide. To start with, the insignificance of the coefficient for air pollution and climate change constitutes an unfavorable result for wind power since it suggests that the main advantage of this technology, compared to conventional electricity generation based on fossil fuels, is not valued significantly among the general population. Improvement of air pollution and climate change is therefore only to a very limited extent an argument in favor of wind power. Since there is no study that values the effect of avoiding nuclear risk by installing wind power, no conclusion can be drawn about the welfare impact of this indirect and positive external effect of wind power. However, the variable indicating whether nuclear power is present as an electricity source in the baseline scenario description suggests that this effect is not significant either. In contrast to the lack of importance of indirect effects, the meta-analysis confirms that the utmost care must be taken with respect to visual impacts that are directly caused by wind turbines. To conclude, visual impacts as direct externalities of wind power affect welfare 
measures significantly and are of high policy relevance whereas indirect (avoided) impacts caused by conventional sources of electricity do not have such effects.

Our analysis indicates that green policies have positive effects on welfare under the assumption that all else remains equal (ceteris paribus). They may therefore constitute an important factor influencing public acceptance or opposition towards wind power projects. This is not to say that green policies can compensate for the negative effects on wind turbines but they may alleviate such effects. If the goal is to expand wind power, a single policy instrument of facilitating the construction of wind turbines (e.g. subsidies or renewable electricity quotas for energy suppliers) may be insufficient to guarantee project success. Rather, a policy mix of subsidies or quotas combined with another green policy, like the setup of a green fund fed by electricity revenues that is earmarked for nature conservation or channeled back to local communities, is expected to yield more promising results.

Caution has to be taken when interpreting the results of this study. First of all, the welfare estimates represent externalities that are heterogeneous and stem from studies using different methodologies and samples. Specifically also, we used data obtained by CE and CV studies. Economic values by both methods highly depend on characteristics of design and methodology. Such are, for example, the attributes chosen, the alternative and the status quo defined, the levels of attributes shown, sample characteristics and other factors. Some of these factors are caused by inherent differences in design between different methods, other factors depend more on decisions taken by the study authors. As an example, in CE we used values reported for scenarios, i.e. values that are adjusted for the level of change in an attribute. As an anonymous reviewer correctly pointed out, the values reported in these cases partly depend on decisions taken by the study authors since there are other possible scenarios that could be reported instead. We acknowledge that this is an issue. However, more often than not scenarios are presented which are most likely also used in practice by policy makers and hence have some degree of realism and credibility. Furthermore, there are procedures to alleviate this issue. Next to assuring as much data homogeneity as data availability permitting during the data collection phase, there are two general steps to minimize the problem in in the context of the more general issue of data heterogeneity in meta-analysis (e.g., Nelson and Kennedy, 2008; Rolfe and Brouwer, 2012). First, the data, and especially the dependent variable, has to be transformed to common units. Second, as many regressors as de- 
grees of freedom permitting have to be included in order to control for as many sources of heterogeneity as possible. In fact, to isolate significant sources of heterogeneity is one of the three main purposes of meta-analysis (Bergstrom and Taylor, 2006). As explained in Chapter 3 above, we followed both steps thoroughly. Considering that we have included control for the valuation method, the size of the change valued, the location (offshore, onshore, both) and other methodological and sample characteristics as well as for the types of externalities evaluated in the scenarios, we are confident that we have managed to control for the most important sources of data heterogeneity. The high performance of our models in terms of explanatory power and average prediction errors support our confidence. A second limitation of this study is the low number of observations. In general, the sample size in meta-analyses can be expanded by broadening the inclusion criteria for the studies. This, however, intensifies the problem of data heterogeneity. As already explained above, our approach in this trade-off was to prioritize data homogeneity over sample size.

Although we were able to present some results on the relative importance of direct and indirect externalities, there are to our knowledge no valuation studies that clearly distinguish and comprehensively value these two categories of external effects. The indirect externalities included in wind power valuation studies focus exclusively on the effects of carbon-based sources of electricity, that is, on the avoidance of air pollution and greenhouse gas emissions. However, nuclear power and sources of renewable energy other than wind also carry negative externalities. Examples include the risk of nuclear accidents and issues associated with nuclear waste disposal or the ecological externalities caused by reduced connectivity of waterbodies and altered flow regimes in the case of hydropower. Including such indirect impacts in assessing the economic value of planned wind turbines and their non-market effects is a promising line for future research.

\section{Acknowledgements}

This research was funded by the Swiss Federal Institute of Aquatic Science and Technology (Eawag) and is part of the Competence Center for Research in Energy, Society and Transition (SCCER CREST). Thanks go to Mehmet Kutluay from the Department of Environmental Economics, Institute for Environ-mental Studies, VU University Amsterdam for his support related to the cross-validation procedure. 


\section{References}

Alvarez-Farizo, B., \& Hanley, N. (2002). Using conjoint analysis to quantify public preferences over the environmental impacts of wind farms. An example from Spain. Energy Policy, 30, 107-116.

Aravena, C., Martinsson, P., \& Scarpa, R. (2014). Does money talk? - The effect of a monetary attribute on the marginal values in a choice experiment. Energy Economics, 44, 483-491.

Bateman, I. J., \& Brouwer, R. (2006). Consistency and construction in stated WTP for health risk reductions: A novel scope-sensitivity test. Resource and Energy Economics, 28(3), 199-214.

Bergmann, A., Hanley, N., \& Wright, R. (2006). Valuing the attributes of renewable energy investments. Energy Policy, 34(9), 1004-1014.

Bergstrom, J. C., \& Taylor, L. O. (2006). Using meta-analysis for benefits transfer: Theory and practice. Ecological Economics, 60(2), 351-360.

Bergström, L., Kautsky, L., Malm, T., Rosenberg, R., Wahlberg, M., Åstrand Capetillo, N., \& Wilhelmsson, D. (2014). Effects of offshore wind farms on marine wildlife - a generalized impact assessment. Environmental Research Letters, 9(3), 034012.

Bishop, I. D., \& Miller, D. R. (2007). Visual assessment of off-shore wind turbines: The influence of distance, contrast, movement and social variables. Renewable Energy, 32(5), 814-831.

Borchers, A., Duke, J., \& Parsons, G. (2007). Does willingness to pay for green energy differ by source? Energy Policy, 35(6), 3327-3334.

Botelho, A., Costa Pinto, L. M., \& Sousa, P. (2013). Valuing wind farms' environmental impacts by geographical distance: A contingent valuation study in Portugal. NIMA Working Paper Series, No. 52.

Brander, L., Brouwer, R., \& Wagtendonk, A. (2013). Economic valuation of regulating services provided by wetlands in agricultural landscapes: A meta-analysis. Ecological Engineering, 56, 89-96.

Brander, L. M., Florax, R. J. G. M., \& Vermaat, J. E. (2006). The empirics of wetland valuation: A comprehensive summary and a meta-analysis of the literature. Environmental and Resource Economics, 33(2), 223-250.

Brouwer, R. (2000). Environmental Value Transfer: State of the Art and Future Prospects. Ecological Economics, 32(1), 137-152.

Cameron, A. C., \& Trivedi, P. K. (2005). Microeconometrics: Methods and Applications. Analysis. New York, NY: Cambridge University Press. 
Carson, R. T. (1997). Contingent valuation surveys and tests of insensitivity to scope. In R. J. Kopp, W. W. Pommerehne, \& N. Schwarz (Eds.), Determining the Value of Non-Marketed Goods: Economic, Psychological, and Policy Relevant Aspects of Contingent Valuation Methods. Boston, MA: Kluwer Academic Publishers.

Carson, R. T., \& Mitchell, R. C. (1993). The Issue of Scope in Contingent Valuation Studies. American Journal of Agricultural Economics, 75(5), 1263-1267.

Champ, P. A., \& Bishop, R. C. (2001). Donation payment mechanisms and contingent valuation: An empirical study of hypothetical bias. Environmental and Resource Economics, 19(4), 383-402.

Cicia, G., Cembalo, L., Del Giudice, T., \& Palladino, A. (2012). Fossil energy versus nuclear, wind, solar and agricultural biomass: Insights from an Italian national survey. Energy Policy, 42, 59-66.

de Ayala, A., Mariel, P., \& Meyerhoff, J. (2014). Transferring landscape values using discrete choice experiments: Is meta-analysis an option? Economia Agraria Y Recursos Naturales, 14(1), 113-128.

Devine-Wright, P. (2005). Beyond NIMBYism: towards an Integrated Framework for Understanding Public Perceptions of Wind Energy. Wind Energy, 8, 125-139.

Dimitropoulos, A., \& Kontoleon, A. (2009). Assessing the determinants of local acceptability of wind-farm investment: A choice experiment in the Greek Aegean Islands. Energy Policy, 37, 1842-1854.

Drewitt, A. L., \& Langston, R. H. W. (2006). Assessing the impacts of wind farms on birds. Ibis, $148,29-42$.

du Preez, M., Menzies, G., Sale, M., \& Hosking, S. (2012). Measuring the indirect costs associated with the establishment of a wind farm: An application of the contingent valuation method. Journal of Energy in Southern Africa, 23(1), 2-7.

ECN Energy Research Centre of the Netherlands. (2011). Renewable Energy Projections as Published in the National Renewable Energy Action Plans of the European Member States. Retrieved from http://forestindustries.eu/sites/default/files/userfiles/1file/e10069.pdf

Ehrlich, Ü., \& Müürsepp, M. (2012). Coastal Area With or Without Wind Turbines: A Contingent Valuation Study in Estonia. Mathematical Modelling and Simulation in Applied Sciences. Proceedings of the 3rd International Conference on Energy, Environment, Devices, Systems, Communications, Computers, 179-184.

Ek, K. (2006). Quantifying the environmental impacts of renewable energy: the case of Swedish wind power. In D. Pearce (Ed.), Environmental Valuation in Develped Countries: Case 
Studies (pp. 181-212). Cheltenham, UK: Edward Elgar Publishing Limited.

Ek, K., \& Matti, S. (2015). Valuing the local impacts of a large scale wind power establishment in northern Sweden: public and private preferences toward economic, environmental and sociocultural values. Journal of Environmental Planning and Management, 58(8), 13271345.

Ek, K., \& Persson, L. (2014). Wind farms - Where and how to place them? A choice experiment approach to measure consumer preferences for characteristics of wind farm establishments in Sweden. Ecological Economics, 105, 193-203.

Erickson, W. P., Johnson, G. D., \& Young Jr., D. P. (2005). A Summary and Comparison of Bird Mortality from Anthropogenic Causes with an Emphasis on Collisions. USDA Forest Service Gen. Tech.

EWEA European Wind Energy Association. (2014). Wind energy scenarios for 2020. Retrieved from http://www.ewea.org/fileadmin/files/library/publications/scenarios/EWEA-Windenergy-scenarios-2020.pdf

Fay, M., Hallegatte, S., Vogt-Schilb, A., Rozenberg, J., Narloch, U., \& Kerr, T. (2015). Decarbonizing Development. Washington, DC: International Bank for Reconstruction and Development / The World Bank.

Fayram, A. H., \& de Risi, A. (2007). The potential compatibility of offshore wind power and fisheries: An example using bluefin tuna in the Adriatic Sea. Ocean and Coastal Management, 50(8), 597-605.

Fimereli, E., \& Mourato, S. (2013). Assessing the effect of energy technology labels on preferences. Journal of Environmental Economics and Policy, 2(3), 245-265.

Fimereli, E., Mourato, S., \& Pearson, P. J. G. (2008). Measuring preferences for low-carbon energy technologies in South-East England: the case of electricity generation. Retrieved from http://orca.cf.ac.uk/40686/

Foster, V., \& Mourato, S. (2003). Elicitation Format and Sensitivity to Scope. Environmental and Resource Economics, 24(2), 141-160.

G7. (2015). Leaders’ Declaration G7 Summit, 7-8 June 2015. Retrieved from https://www.g7germany.de/Content/DE/_Anlagen/G8_G20/2015-06-08-g7-abschlusseng.pdf?_blob=publicationFile\&v=5

Gill, A. B., Bartlett, M., \& Thomsen, F. (2012). Potential interactions between diadromous fishes of U.K. conservation importance and the electromagnetic fields and subsea noise from marine renewable energy developments. Journal of Fish Biology, 81(2), 664-695.

Goldberg, I., \& Roosen, J. (2007). Scope insensitivity in health risk reduction studies: A 
comparison of choice experiments and the contingent valuation method for valuing safer food. Journal of Risk and Uncertainty, 34(2), 123-144.

Groothuis, P. A., Groothuis, J. D., \& Whitehead, J. C. (2008). Green vs. green: Measuring the compensation required to site electrical generation windmills in a viewshed. Energy Policy, 36(4), 1545-1550.

Guo, X., Liu, H., Mao, X., Jin, J., Chen, D., \& Cheng, S. (2014). Willingness to pay for renewable electricity: A contingent valuation study in Beijing, China. Energy Policy, 68, 340-347.

GWEC Global Wind Energy Council. (2012). Global Wind Statistics 2012. Retrieved from http://www.gwec.net/wp-content/uploads/2013/02/GWEC-PRstats-2012_english.pdf

Haggett, C. (2011). Understanding public responses to offshore wind power. Energy Policy, 39(2), 503-510.

Hamilton, L. C. (2012). Statistics with STATA Version 12. Boston, MA: Cengage Learning.

Hanley, N., \& Nevin, C. (1999). Appraising renewable energy developments in remote communities: the case of the North Assynt Estate, Scotland. Energy Policy, 27(9), 527-547.

Harbord, R. M., \& Higgins, J. P. T. (2008). Meta-regression in Stata. The Stata Journal, 8(4), 493-519.

Harrison, G. W., Lau, M. I., \& Melonie, B. (2000). Estimating Individual Discount Rates in Denmark : A Field Experiment. Business, 92(5), 1606-1617.

Harrison, J. P. (2011). Wind Turbine Noise. Bulletin of Science, Technology \& Society, 31(4), 256-261.

Haughton, J., Tuerck, D. G., Giuffre, D., \& Barrett, J. (2004). An Economic Analysis of a Wind Farm in Nantucket Sound. Boston, MA. Retrieved from http://www.beaconhill.org/BHIStudies/Windmills2004/WindFarmArmyCorps.pdf

Hökby, S., \& Söderqvist, T. (2003). Elasticities of Demand and Willingness to Pay for Environmental Services in Sweden. Environmental and Resource Economics, 26(3), 361383.

IEA International Energy Agency. (2011). China Wind Energy Development Roadmap 2050. Retrieved from https://www.iea.org/publications/freepublications/publication/china_wind.pdf

IEA International Energy Agency. (2014a). Energy Statistics of Non-OECD Countries. Paris. Retrieved from http://www.oecdilibrary.org/docserver/download/6114161e.pdf?expires=1431531595\&id=id\&accname=oid0 
21321\&checksum=2FA292B1A4254241154525A0B0A747CD

IEA International Energy Agency. (2014b). Energy Statistics of OECD Countries. Paris. Retrieved from http://www.oecdilibrary.org/docserver/download/6114171e.pdf?expires=1431531699\&id=id\&accname=oid0 21321\&checksum=4D3352DF97AA9509602DD572AB5B339C

Jacobsen, J. B., \& Hanley, N. (2009). Are there income effects on global willingness to pay for biodiversity conservation? Environmental and Resource Economics, 43(2), 137-160.

Johansson, M., \& Laike, T. (2007). Intention to respond to local wind turbines: The role of attitudes and visual perception. Wind Energy, 10(5), 435-451.

Kontogianni, A., Tourkolias, C., \& Skourtos, M. (2013). Renewables portfolio, individual preferences and social values towards RES technologies. Energy Policy, 55, 467-476.

Kosenius, A.-K., \& Ollikainen, M. (2013). Valuation of environmental and societal trade-offs of renewable energy sources. Energy Policy, 62, 1148-1156.

Koundouri, P., Kountouris, Y., \& Remoundou, K. (2009). Valuing a wind farm construction: A contingent valuation study in Greece. Energy Policy, 37(5), 1939-1944.

Kristrom, B., \& Riera, P. (1996). Is the income elasticity of environmental improvements less than one? Environmental and Resource Economics, 7(1), 45-55.

Krueger, A. D. (2007). Valuing Public Preferences for Offshore Wind Power: A Choice Experiment Approach. PhD Thesis. University of Delaware.

Ku, S.-J., \& Yoo, S.-H. (2010). Willingness to pay for renewable energy investment in Korea: A choice experiment study. Renewable and Sustainable Energy Reviews, 14(8), 2196-2201.

Ladenburg, J. (2008). Attitudes towards on-land and offshore wind power development in Denmark; choice of development strategy. Renewable Energy, 33(1), 111-118.

Ladenburg, J., \& Dubgaard, A. (2009). Preferences of coastal zone user groups regarding the siting of offshore wind farms. Ocean and Coastal Management, 52(5), 233-242.

Lancaster, K. J. (1966). A New Approach to Consumer Theory. The Journal of Political Economy, 74(2), 132-157.

Landry, C. E., Allen, T., Cherry, T., \& Whitehead, J. C. (2012). Wind turbines and coastal recreation demand. Resource and Energy Economics, 34(1), 93-111.

Leung, D. Y. C., \& Yang, Y. (2012). Wind energy development and its environmental impact: A review. Renewable and Sustainable Energy Reviews, 16(1), 1031-1039.

Li, H., Jenkins-Smith, H. C., Silva, C. L., Berrens, R. P., \& Herron, K. G. (2009). Public support for reducing US reliance on fossil fuels: Investigating household willingness-to-pay for 
energy research and development. Ecological Economics, 68(3), 731-742.

Lipsey, M. W., \& Wilson, D. B. (2001). Practical Meta-Analysis. Thousand Oaks, London, New Delhi: Sage Publications.

Longo, A., Markandya, A., \& Petrucci, M. (2008). The internalization of externalities in the production of electricity: Willingness to pay for the attributes of a policy for renewable energy. Ecological Economics, 67(1), 140-152.

MacMillan, D., Hanley, N., \& Lienhoop, N. (2006). Contingent valuation: Environmental polling or preference engine? Ecological Economics, 60(1), 299-307.

Mariel, P., Meyerhoff, J., \& Hess, S. (2015). Heterogeneous preferences toward landscape externalities of wind turbines - combining choices and attitudes in a hybrid model. Renewable and Sustainable Energy Reviews, 41, 647-657.

Mathew, S. (2006). Wind Energy. Fundamentals, Resources Analysis and Economics. Berlin Heidelberg: Springer.

McCartney, A. (2006). The social value of seascapes in the Jurien Bay Marine Park: An assessment of positive and negative preferences for change. Journal of Agricultural Economics, 57(3), 577-594.

Meyerhoff, J., Ohl, C., \& Hartje, V. (2010). Landscape externalities from onshore wind power. Energy Policy, 38(1), 82-92.

Mez, L. (2012). Nuclear energy - Any solution for sustainability and climate protection? Energy Policy, 48, 56-63.

Mirasgedis, S., Tourkolias, C., Tzovla, E., \& Diakoulaki, D. (2014). Valuing the visual impact of wind farms: An application in South Evia, Greece. Renewable and Sustainable Energy Reviews, 39, 296-311.

Mozumder, P., Vásquez, W. F., \& Marathe, A. (2011). Consumers’ preference for renewable energy in the southwest USA. Energy Economics, 33(6), 1119-1126.

Navrud, S., \& Bråten, G. (2007). Consumers' Preferences for Green and Brown Electricity : A Choice Modelling Approach. Revue d'Économie Politique, 117, 795-811.

Nelson, J. P., \& Kennedy, P. E. (2008). The Use (and Abuse) of Meta-Analysis in Environmental and Natural Resource Economics: An Assessment. Environmental and Resource Economics, 42(3), 345-377.

Nomura, N., \& Akai, M. (2004). Willingness to pay for green electricity in Japan as estimated through contingent valuation method. Applied Energy, 78(4), 453-463.

OECD. (2014). OECD. Stat (database). Retrieved from http://www.oecd-ilibrary.org/statistics 
Ohman, M. C., Sigray, P., \& Westerberg, H. (2007). Offshore windmills and the effects of electromagnetic fields on fish. Ambio, 36(8), 630-633.

Ojea, E., \& Loureiro, M. L. (2011). Identifying the scope effect on a meta-analysis of biodiversity valuation studies. Resource and Energy Economics, 33(3), 706-724.

Pasqualetti, M. J. (2011). Opposing Wind Energy Landscapes: A Search for Common Cause. Annals of the Association of American Geographers, 101(4), 907-917.

Pasqualetti, M. J., Gipe, P., \& Righter, R. W. (2002). Wind Power in View. London: Academic Press.

PBL Netherlands Environmental Assessment Agency. (2014). Trends in global CO2 emissions: 2014 Report. Retrieved from http://edgar.jrc.ec.europa.eu/news_docs/jrc-2014-trends-inglobal-co2-emissions-2014-report-93171.pdf

Pedersen, E. (2011). Health aspects associated with wind turbine noise-Results from three field studies. Noise Control Engineering Journal, 59(1), 47-53.

Pedersen, E., \& Larsman, P. (2008). The impact of visual factors on noise annoyance among people living in the vicinity of wind turbines. Journal of Environmental Psychology, 28(4), 379-389.

Pedersen, E., \& Persson Waye, K. (2007). Wind turbine noise, annoyance and self-reported health and well-being in different living environments. Occupational and Environmental Medicine, 64(7), 480-486.

Petersen, J. K., \& Malm, T. (2006). Offshore Windmill Farms: Threats to or Possibilities for the Marine Environment. Ambio, 35(2), 75-80.

Ringquist, E. J. (2013). Meta-Analysis for Public Management and Policy. San Francisco: Jossey-Bass.

Roe, B., Teisl, M. F., Levy, A., \& Russell, M. (2001). US consumers' willingness to pay for green electricity. Energy Policy, 29(11), 917-925.

Rolfe, J., \& Brouwer, R. (2012). Design effects in a meta-analysis of river health choice experiments in Australia. Journal of Choice Modelling, 5(2), 81-97.

Rosenberger, R. S., \& Stanley, T. D. (2006). Measurement, generalization, and publication: Sources of error in benefit transfers and their management. Ecological Economics, 60(2), 372-378.

Smith, V. K., \& Osborne, L. L. (1996). Do contingent valuation estimates pass a “'scope”" test? A meta-analysis. Journal of Environmental Economics and Management, 31(3), 287-301.

Smith, V. K., \& Pattanayak, S. K. (2002). Is meta-analysis a Noah’s ark for non-market 
valuation? Environmental and Resource Economics, 22(1), 271-296.

Strazzera, E., Mura, M., \& Contu, D. (2012). Combining choice experiments with psychometric scales to assess the social acceptability of wind energy projects: A latent class approach. Energy Policy, 48, 334-347.

U.S. Energy Information Administration (EIA). (2012). International Energy Statistics. Retrieved from http://www.eia.gov/cfapps/ipdbproject/IEDIndex3.cfm?tid=6\&pid=29\&aid=12

van den Bergh, J. C., Button, K. J., Nijkamp, P., \& Pepping, G. C. (1997). Meta-Analysis in Environmental Economics. Dordrecht: Kluwer.

van der Loo, F. (2001). Mediating Windpower in the Netherlands: the Task Force Windpower Implementation. Utrecht: Novem.

Vecchiato, D. (2014). How do you like wind farms? Understanding people's preferences about new energy landscapes with choice experiments. Aestimum, 64(1), 15-37.

Wahlberg, M., \& Westerberg, H. (2005). Fish Hearing and reactions to Sounds from Offshore Wind Farms. Marine Ecology Progress Series, 288, 295-309.

Warren, C. R., Lumsden, C., O’Dowd, S., \& Birnie, R. V. (2005). “Green On Green”: Public Perceptions of Wind Power in Scotland and Ireland. Journal of Environmental Planning and Management, 48(6), 853-875.

Weisser, D. (2007). A guide to life-cycle greenhouse gas (GHG) emissions from electric supply technologies. Energy, 32(9), 1543-1559.

Westerberg, V., Jacobsen, J. B., \& Lifran, R. (2013). The case for offshore wind farms, artificial reefs and sustainable tourism in the French mediterranean. Tourism Management, 34, 172183.

Whitehead, J. C., \& Cherry, T. L. (2007). Willingness to pay for a Green Energy program: A comparison of ex-ante and ex-post hypothetical bias mitigation approaches. Resource and Energy Economics, 29(4), 247-261.

Wilson, J. C., \& Elliott, M. (2009). The habitat-creation potential of offshore wind farms. Wind Energy, 12(2), 203-212.

Wolsink, M. (2000). Wind power and the NIMBY-myth: institutional capacity and the limited significance of public support. Renewable Energy, 21(1), 49-64.

Wolsink, M. (2007). Wind power implementation: The nature of public attitudes: Equity and fairness instead of "backyard motives." Renewable and Sustainable Energy Reviews, 11(6), $1188-1207$.

Wüstenhagen, R., Wolsink, M., \& Bürer, M. J. (2007). Social acceptance of renewable energy 
innovation: An introduction to the concept. Energy Policy, 35(5), 2683-2691. 
Figure 1. Histograms of the standard errors of model predictions based on 10,000 iterations
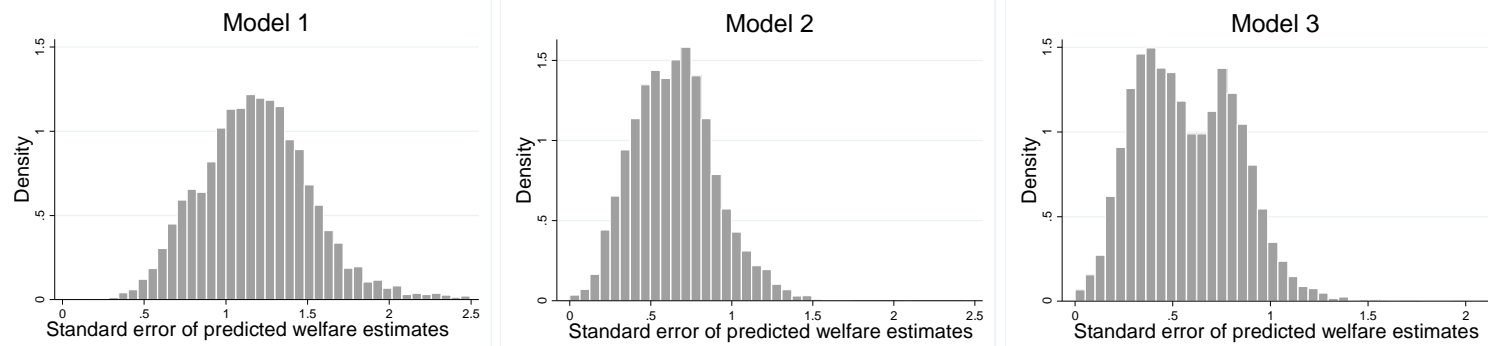
Table 1. Non-market valuation studies of wind power externalities listed by study year

\begin{tabular}{|c|c|c|c|c|c|c|}
\hline ID & $\begin{array}{l}\text { Study } \\
\text { year }\end{array}$ & $\begin{array}{l}\text { Authors (year of } \\
\text { publication) }\end{array}$ & $\begin{array}{l}\text { Type of publication (Journal } \\
\text { name) }\end{array}$ & Country & $\begin{array}{l}\text { National wind } \\
\text { power share }^{\text {a }}\end{array}$ & $\begin{array}{l}\text { Valuation } \\
\text { method }\end{array}$ \\
\hline 1 & 1998 & $\begin{array}{l}\text { Hanley and Nevin } \\
\text { (1999) }\end{array}$ & Journal article (Energy Policy) & $\begin{array}{l}\text { United } \\
\text { Kingdom }\end{array}$ & $0.25 \%$ & $\mathrm{CV}$ \\
\hline 2 & 1998 & $\begin{array}{l}\text { Alvarez-Farizo and } \\
\text { Hanley (2002) }\end{array}$ & Journal article (Energy Policy) & Spain & $2.90 \%$ & CE \\
\hline 3 & 2000 & $\begin{array}{l}\text { Nomura and Akai } \\
\text { (2004) }\end{array}$ & $\begin{array}{l}\text { Journal article (Applied } \\
\text { Energy) }\end{array}$ & Japan & $0.02 \%$ & $\mathrm{CV}$ \\
\hline 4 & 2001 & $\begin{array}{l}\text { Champ and Bishop } \\
(2001)\end{array}$ & $\begin{array}{l}\text { Journal article (Environmental } \\
\text { and Resource Economics) }\end{array}$ & USA & $0.18 \%$ & $\mathrm{CV}$ \\
\hline 5 & 2002 & $\begin{array}{l}\text { Whitehead and } \\
\text { Cherry (2007) }\end{array}$ & $\begin{array}{l}\text { Journal article (Resource and } \\
\text { Energy Economics) }\end{array}$ & USA & $0.26 \%$ & CV \\
\hline 6 & 2003 & $\begin{array}{l}\text { Bergmann et al. } \\
(2006)\end{array}$ & Journal article (Energy Policy) & $\begin{array}{l}\text { United } \\
\text { Kingdom }\end{array}$ & $0.32 \%$ & CE \\
\hline 7 & 2003 & $\begin{array}{l}\text { MacMillan et al. } \\
(2006)\end{array}$ & $\begin{array}{l}\text { Journal article (Ecological } \\
\text { Economics) }\end{array}$ & $\begin{array}{l}\text { United } \\
\text { Kingdom }\end{array}$ & $0.32 \%$ & $\mathrm{CV}$ \\
\hline 8 & 2003 & $\begin{array}{l}\text { Haughton et al. } \\
(2004)\end{array}$ & $\begin{array}{l}\text { Report (The Beacon Hill Insti- } \\
\text { tute) }\end{array}$ & USA & $0.26 \%$ & $\mathrm{CV}$ \\
\hline 9 & 2004 & $\begin{array}{l}\text { Ladenburg and } \\
\text { Dubgaard (2009) }\end{array}$ & $\begin{array}{l}\text { Journal article (Ocean \& } \\
\text { Coastal Management) }\end{array}$ & Denmark & $16.28 \%$ & CE \\
\hline 10 & 2005 & Longo et al. (2008) & $\begin{array}{l}\text { Journal article (Ecological } \\
\text { Economics) }\end{array}$ & $\begin{array}{l}\text { United } \\
\text { Kingdom }\end{array}$ & $0.73 \%$ & CE \\
\hline 11 & 2005 & $\begin{array}{l}\text { Navrud and Bråten } \\
(2007)\end{array}$ & $\begin{array}{l}\text { Journal article (Revue } \\
\text { d'economie politique) }\end{array}$ & Norway & $0.36 \%$ & CE \\
\hline 12 & 2006 & Ku and Yoo (2010) & $\begin{array}{l}\text { Journal article (Renewable } \\
\text { and Sustainable Energy Re- } \\
\text { views) }\end{array}$ & $\begin{array}{l}\text { South } \\
\text { Korea }\end{array}$ & $0.06 \%$ & CE \\
\hline 13 & 2006 & Li et al. (2009) & $\begin{array}{l}\text { Journal article (Ecological } \\
\text { Economics) }\end{array}$ & USA & $0.62 \%$ & $\mathrm{CV}$ \\
\hline 14 & 2006 & Krueger (2007) & $\mathrm{PhD}$ thesis & USA & $0.62 \%$ & CE \\
\hline 15 & 2006 & Borchers et al. (2007) & Journal article (Energy Policy) & USA & $0.62 \%$ & CE \\
\hline 16 & 2006 & McCartney (2006) & $\begin{array}{l}\text { Journal article (Journal of } \\
\text { Agriculture Economics) }\end{array}$ & Australia & $0.74 \%$ & CV \\
\hline 17 & 2007 & $\begin{array}{l}\text { Koundouri et al. } \\
(2009)\end{array}$ & Journal article (Energy Policy) & Greece & $2.90 \%$ & $\mathrm{CV}$ \\
\hline 18 & 2008 & $\begin{array}{l}\text { Fimereli et al. (2008, } \\
\text { 2013) }\end{array}$ & $\begin{array}{l}\text { Journal article (Journal of } \\
\text { Environmental Economics and } \\
\text { Policy) }\end{array}$ & $\begin{array}{l}\text { United } \\
\text { Kingdom }\end{array}$ & $1.84 \%$ & CE \\
\hline 19 & 2008 & $\begin{array}{l}\text { Kosenius and } \\
\text { Ollikainen (2013) }\end{array}$ & Journal article (Energy Policy) & Finland & $0.34 \%$ & CE \\
\hline 20 & 2008 & Mariel et al. (2015) & $\begin{array}{l}\text { Journal article (Renewable } \\
\text { and Sustainable Energy Re- } \\
\text { views) }\end{array}$ & Germany & $1.80 \%$ & CE \\
\hline 21 & 2009 & Cicia et al. (2012) & Journal article (Energy Policy) & Italy & $2.27 \%$ & CE \\
\hline 22 & 2009 & Landry et al. (2012) & $\begin{array}{l}\text { Journal article (Resource and } \\
\text { Energy Economics) }\end{array}$ & USA & $1.77 \%$ & CE \\
\hline 23 & 2010 & Guo et al. (2014) & Journal article (Energy Policy) & China & $1.06 \%$ & CV \\
\hline
\end{tabular}




\begin{tabular}{|c|c|c|c|c|c|c|}
\hline 24 & 2010 & $\begin{array}{l}\text { Kontogianni et al. } \\
(2013)\end{array}$ & Journal article (Energy Policy) & Greece & $4.73 \%$ & $\mathrm{CV}$ \\
\hline 25 & 2010 & $\begin{array}{l}\text { Westerberg et al. } \\
(2013)\end{array}$ & $\begin{array}{l}\text { Journal article (Tourism Man- } \\
\text { agement) }\end{array}$ & France & $1.77 \%$ & CE \\
\hline 26 & 2010 & Ek and Matti (2015) & $\begin{array}{l}\text { Journal article (Journal of } \\
\text { Environmental Planning and } \\
\text { Management) }\end{array}$ & Sweden & $2.36 \%$ & CE \\
\hline 27 & 2011 & $\begin{array}{l}\text { Ek and Persson } \\
(2014)\end{array}$ & $\begin{array}{l}\text { Journal article (Ecological } \\
\text { Economics) }\end{array}$ & Sweden & $4.05 \%$ & CE \\
\hline 28 & 2011 & $\begin{array}{l}\text { Mozumder et al. } \\
(2011)\end{array}$ & $\begin{array}{l}\text { Journal article (Energy Eco- } \\
\text { nomics) }\end{array}$ & USA & $2.78 \%$ & CV \\
\hline 29 & 2011 & Vecchiato (2014) & Journal article (Aestimum) & Italy & $3.37 \%$ & CE \\
\hline 30 & 2012 & $\begin{array}{l}\text { Mirasgedis et al. } \\
(2014)\end{array}$ & $\begin{array}{l}\text { Journal article (Renewable } \\
\text { and Sustainable Energy Re- } \\
\text { views) }\end{array}$ & Greece & $6.69 \%$ & $\mathrm{CV}$ \\
\hline 31 & 2012 & Botelho et al. (2013) & Working paper & Portugal & $22.53 \%$ & $\mathrm{CV}$ \\
\hline 32 & 2012 & $\begin{array}{l}\text { Ehrlich and Müürsepp } \\
\text { (2012) }\end{array}$ & Conference proceedings & Estonia & $0.40 \%$ & $\mathrm{CV}$ \\
\hline
\end{tabular}

\footnotetext{
${ }^{a}$ IEA, 2014a, 2014b
} 
Table 2. Classification of externalities valued

\begin{tabular}{|c|c|c|c|c|c|c|c|c|c|c|c|c|c|c|c|c|c|c|c|c|c|c|}
\hline Study-ID: & 1 & 23 & 34 & 5 & 6 & 7 & 8 & 9 & 1011 & 12 & 1314 & 41516 & 6171 & & 1920 & 21222 & 2324 & 2526 & 272 & 282930 & 3132 & $2 N$ \\
\hline Air Pollution and climate change & & & & & & & & & & & & & & & & & & & & & & 17 \\
\hline Avoiding emissions in general & & & & & $x$ & & & & $x$ & $x$ & $x$ & $x$ & & & & & $x$ & & & $x$ & & 7 \\
\hline Avoiding greenhouse gas emissions & & $x$ & $x$ & & & $x$ & & & $x$ & & & & & $x \quad x$ & $x$ & $\mathrm{x}$ & $x$ & & & & $\mathrm{x}$ & 8 \\
\hline $\begin{array}{l}\text { Improvement of air quality (impacts on visibility, acid } \\
\text { rain, respiratory problems) }\end{array}$ & & & & $\mathrm{x}$ & & & & & & & & & & & & & & & & & & 1 \\
\hline Avoiding environmental drawbacks of coal & & & $x$ & & & & & & & & & & & & & & & & & & & 1 \\
\hline Fuel independence & & & & & & & & & & & & & & & & & & & & & & 3 \\
\hline No fossil fuels needed & & & & & & & & & & & & $x$ & & & & & & & & & & 1 \\
\hline Independence from oil & & & & & & & & & & & $x$ & & & & & & & & & & & 1 \\
\hline No water used & & & & & & & & & & & & & & & & & & & & $x$ & & 1 \\
\hline Biodiversity & & & & & & & & & & & & & & & & & & & & & & 11 \\
\hline Effects on biodiversity & & & & & & & & & & $x$ & & & & $x \quad x$ & $x$ & & & & & & & 3 \\
\hline Effects on habitat and flora & & $\mathrm{x}$ & & & & & & & & & & & & & & & & & & & & 1 \\
\hline Effects on fauna and bird life & $x$ & $x$ & $x$ & & & & & & $x$ & & & $x$ & & & $x$ & & & $x$ & & & & 7 \\
\hline Visual impacts & & & & & & & & & & & & & & & & & & & & & & 21 \\
\hline Terrestrial visual impacts & $x$ & $\mathrm{x}$ & $x$ & & $\mathrm{x}$ & $\mathrm{x}$ & & & $x$ & & & $x$ & $x$ & & & $\mathrm{x}$ & & & & $x \quad x$ & $\mathrm{x}$ & 12 \\
\hline Marine/coastal visual impacts & & & & & & & $\mathrm{x}$ & $\mathrm{x}$ & & & $x$ & $\mathrm{x}$ & & & & $x$ & & $\mathrm{x}$ & & $\mathrm{x}$ & $\mathrm{x}$ & 8 \\
\hline Visual impacts associated with residential proximity & & & & & & & & & & & & & & $\mathrm{x}$ & $x$ & & & & & & & 2 \\
\hline Noise impacts & & & $x$ & & & & & & $\mathrm{x}$ & & & & & & $x$ & $\mathrm{x}$ & & & & & $\mathrm{x}$ & 5 \\
\hline Green policy & & & & & & & & & & & & & & & & & & & & & & 3 \\
\hline $\begin{array}{l}\text { Transfer of some electricity revenue to local } \\
\text { community earmarked for nature conservation }\end{array}$ & & & & & & & & & & & & & & & & & & & $x$ & & & 1 \\
\hline Royalty fund for green purposes & & & & & & & & & & & $\mathrm{x}$ & & & & & & & & & & & 1 \\
\hline Coherent environmental policy & & & & & & & & & & & & & & & & & & $x$ & & & & 1 \\
\hline Other & & & & & & & & & & & & & & & & & & & & & & 4 \\
\hline Location & & & & & & & & & & & & & & & & & & & $\mathrm{x}$ & & & 1 \\
\hline Type of ownership (state, private, cooperative, etc.) & & & & & & & & & & & & & & & & & & & $x$ & & & 1 \\
\hline Stakeholder consultation & & & & & & & & & & & & & & & & & & & $x$ & & & 1 \\
\hline Reduced number of blackouts & & & & & & & & & $\mathrm{x}$ & & & & & & & & & & & & & 1 \\
\hline Land area affected & & & & & & & & & & & & $x$ & & & & & & & & & & 1 \\
\hline Recreational activities associated with an artificial reef & & & & & & & & & & & & & & & & & & $\mathrm{x}$ & & & & 1 \\
\hline
\end{tabular}


Table 3. Types of externalities included in the meta-analysis

\begin{tabular}{|c|c|c|}
\hline Variable & Description & Coding of variables \\
\hline $\begin{array}{l}\text { Air pollution and } \\
\text { climate change } \\
\text { (improvement) }\end{array}$ & $\begin{array}{l}\text { Avoidance of air pollution and climate change (including green- } \\
\text { house gas emissions) }\end{array}$ & $\begin{array}{l}\text { Dummy: } 1=\text { Air pollution and } \\
\text { climate change avoidance } \\
\text { valued; } 0=\text { Otherwise }\end{array}$ \\
\hline $\begin{array}{l}\text { Biodiversity } \\
\text { (improvement) }\end{array}$ & $\begin{array}{l}\text { Improvements and mitigations of negative effects on biodiversity, } \\
\text { e.g. birds, habitat and flora }\end{array}$ & $\begin{array}{l}\text { Dummy: } 1=\text { Biodiversity im- } \\
\text { provement and mitigation } \\
\text { measures valued; } 0=\text { Otherwise }\end{array}$ \\
\hline $\begin{array}{l}\text { Biodiversity } \\
\text { (deterioration) }\end{array}$ & $\begin{array}{l}\text { Deteriorations of biodiversity, e.g. negative effects on birds and } \\
\text { other animals }\end{array}$ & $\begin{array}{l}\text { Dummy: } 1=\text { Deterioration of } \\
\text { biodiversity valued; } \\
0=\text { Otherwise }\end{array}$ \\
\hline $\begin{array}{l}\text { Visual effects } \\
\text { (improvement) }\end{array}$ & $\begin{array}{l}\text { Improvements and mitigations of negative visual effects caused } \\
\text { by wind turbines, e.g. visual impacts on landscapes, views and } \\
\text { in general visual effects caused by the proximity to residential } \\
\text { areas }\end{array}$ & $\begin{array}{l}\text { Dummy: } 1=\text { Improvement of } \\
\text { visual effects valued; } \\
0=\text { Otherwise }\end{array}$ \\
\hline $\begin{array}{l}\text { Visual effects } \\
\text { (deterioration) }\end{array}$ & $\begin{array}{l}\text { Deteriorations of visual effects caused by wind turbines, e.g. } \\
\text { visual impacts on landscapes and shores }\end{array}$ & $\begin{array}{l}\text { Dummy: } 1=\text { Deterioration of } \\
\text { visual effects valued; } \\
0=\text { Otherwise }\end{array}$ \\
\hline $\begin{array}{l}\text { Green policy } \\
\text { (improvement) }\end{array}$ & $\begin{array}{l}\text { Introduction of a coherent environmental policy or transfer of a } \\
\text { share of the wind power provider's revenue to the local commu- } \\
\text { nity earmarked for nature conservation measures or the promo- } \\
\text { tion of renewable energy }\end{array}$ & $\begin{array}{l}\text { Dummy: } 1=\text { Green policy im- } \\
\text { plementation valued; } \\
0=\text { Otherwise }\end{array}$ \\
\hline
\end{tabular}


Table 4. Classification of methodological and sample characteristics

\begin{tabular}{|c|c|c|c|c|c|c|c|c|c|c|c|c|c|c|c|c|c|c|c|c|c|c|c|c|c|c|c|c|c|c|c|c|}
\hline Study-ID & 1 & 2 & 3 & 4 & 5 & 6 & 7 & 8 & 9 & 101 & 111 & 1213 & 14 & 15 & 161 & 17 & 18 & 19 & 20 & 21 & 22 & 23 & 242 & 25 & 262 & 27 & 28 & 29 & 30 & 31 & 32 & $\bar{N}$ \\
\hline \multicolumn{33}{|l|}{ Valuation method } \\
\hline Choice Experiments & & $x$ & & & & $x$ & & & $x$ & $\mathrm{x}$ & $x>$ & $x$ & $x$ & $x$ & & & $x$ & $x$ & $x$ & $x$ & $x$ & & & $x$ & $x$ & $x$ & & $x$ & & & & 17 \\
\hline Contingent valuation $(\mathrm{SB}, \mathrm{DB}, \mathrm{PC}, \mathrm{OE})^{\mathrm{a}}$ & $\mathrm{PC}$ & & DB & SB $\varsigma$ & SB & & $\mathrm{PC}$ & OE & & & & SB & & & DB D & DB & & & & & & SB & OE & & & & OE & & OE & OE & OE & 15 \\
\hline \multicolumn{33}{|l|}{ Survey mode } \\
\hline Face-to-face & $x$ & $x$ & & & & & $x$ & $\mathrm{x}$ & & $\mathrm{x}$ & $x>$ & $x$ & & $x$ & $x$ & & & & & & & $x$ & $\mathrm{x}$ & $\mathrm{x}$ & & & & & & $x$ & $\mathrm{x}$ & 12 \\
\hline Mail & & & $x$ & $x$ & & $x$ & & & $\mathrm{x}$ & & & & $x$ & & & & $x$ & & & & & & & & $x$ & & & & & & & 7 \\
\hline Online & & & & & & & & & & & & $x$ & & & & & & $x$ & & & $x$ & & & & & $x$ & $x$ & $x$ & & $x$ & & 7 \\
\hline Telephone & & & & & $x$ & & & & & & & $x$ & & & & $x$ & & & $x$ & $x$ & & & & & & & & & $x$ & & & 6 \\
\hline \multicolumn{33}{|l|}{ Payment vehicle } \\
\hline Electricity costs & & & $x$ & $x$ & $x$ & $x$ & $x$ & & $x$ & $\mathrm{x}$ & $x>$ & $x \quad x$ & $x$ & $x$ & $x$ & $x$ & $x$ & $x$ & $x$ & $x$ & & $x$ & & $x$ & & $x$ & $x$ & $x$ & $x$ & $x$ & & 25 \\
\hline Taxes & & $x$ & & & & & & & & & & & & & & & & & & & & & & & & & & & & & $x$ & 2 \\
\hline Contribution to a fund & $x$ & & & & & & & $x$ & & & & & & & & & & & & & & & & & $x$ & & & & & & & 3 \\
\hline Parking fee & & & & & & & & & & & & & & & & & & & & & $x$ & & & & & & & & & & & 1 \\
\hline Accommodation price & & & & & & & & & & & & & & & & & & & & & & & $x$ & & & & & & & & & 1 \\
\hline \multicolumn{33}{|l|}{ Payment frequency } \\
\hline Annual & $x$ & $x$ & & $x$ & & $x$ & $x$ & & $x$ & & $x$ & $x$ & & & & & $x$ & $x$ & & & $x$ & & $x$ & & & $x$ & & $x$ & & $x$ & $x$ & 16 \\
\hline Monthly & & & $x$ & & $x$ & & & & & & & $x$ & $x$ & $x$ & & & & & $x$ & & & $x$ & & & & & $x$ & & & & & 8 \\
\hline Bi-monthly & & & & & & & & & & & & & & & & $x$ & & & & $x$ & & & & & & & & & $x$ & & & 3 \\
\hline Quarterly & & & & & & & & & & $x$ & & & & & & & & & & & & & & & & & & & & & & 1 \\
\hline One-off & & & & & & & & $x$ & & & & & & & $x$ & & & & & & & & & & $x$ & & & & & & & 3 \\
\hline Per trip & & & & & & & & & & & & & & & & & & & & & & & & $x$ & & & & & & & & 1 \\
\hline \multicolumn{33}{|l|}{ Payment duration } \\
\hline Indefinite & $x$ & $x$ & $x$ & & $x$ & $x$ & $x$ & & $x$ & $\mathrm{x}$ & $x>$ & $x \quad x$ & & $x$ & & $x$ & $x$ & $x$ & $x$ & $x$ & $x$ & & $x$ & $x$ & & $x$ & $x$ & $x$ & $x$ & $x$ & $\mathrm{x}$ & 26 \\
\hline 5 years & & & & & & & & & & & & & & & & & & & & & & $x$ & & & & & & & & & & 1 \\
\hline 3 years & & & & & & & & & & & & & $x$ & & & & & & & & & & & & & & & & & & & 1 \\
\hline 1 year & & & & $x$ & & & & & & & & & & & & & & & & & & & & & & & & & & & & 1 \\
\hline One-off & & & & & & & & $x$ & & & & & & & $x$ & & & & & & & & & & $x$ & & & & & & & 3 \\
\hline \multicolumn{33}{|l|}{ Continent } \\
\hline Europe & UK & & & & & UK & UK & & DK & UK N & NO & & & & & GR & UK & $\mathrm{FI}$ & $\mathrm{DE}$ & IT & & & GR & FR & SE $S$ & SE & & & GR & PT & EE & 20 \\
\hline North America & & & & US I & & & & US & & & & US & US & US & & & & & & & US & & & & & & US & & & & & 8 \\
\hline Asia & & & $\mathrm{JP}$ & & & & & & & & & $\mathrm{KR}$ & & & & & & & & & & $\mathrm{CN}$ & & & & & & & & & & 3 \\
\hline
\end{tabular}


Australia

$\mathrm{AU}$

Facility location

Onshore

Offshore

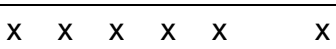

$x$

$x$

$x$

Both

$x$

$\mathrm{x}$

$\mathrm{x} x$

$x^{x}$

$x \quad x$

$x$

$x$

$x \quad x$

18

Visualizations used in the survey

\begin{tabular}{|c|c|c|c|c|c|c|c|c|c|c|c|c|c|c|c|c|c|c|c|c|c|c|c|c|c|c|c|c|c|c|c|c|c|}
\hline Yes & $x$ & $x$ & & & & & & $x$ & $x$ & $x$ & & & & $x$ & & $x$ & & $x$ & & & & $x$ & $x$ & & $x$ & & $x$ & & $x$ & & & & 13 \\
\hline No & & & & $x$ & $\mathrm{x}$ & $x$ & $x$ & & & & $x$ & $x$ & $x$ & & $x$ & & $x$ & & $x$ & $x$ & $x$ & & & $x$ & & $x$ & & $x$ & & $x$ & $x$ & $x$ & 19 \\
\hline Sample & & & & & & & & & & & & & & & & & & & & & & & & & & & & & & & & & \\
\hline Visitors & & & & & & & & $x$ & & & & & & & & & & & & & & $x$ & & & $x$ & & & & & & & & 3 \\
\hline Local residents & $x$ & $x$ & & $x$ & $x$ & & & $x$ & $x$ & & & & & $x$ & $x$ & $x$ & $x$ & & & & & & $x$ & $x$ & & $x$ & & $x$ & & $x$ & $x$ & & 16 \\
\hline Non-users & & & & & & $x$ & $x$ & & $x$ & $x$ & $x$ & $x$ & $x$ & $x$ & & & & $x$ & $x$ & $x$ & $x$ & & & & & & $x$ & & $x$ & & $x$ & $x$ & 17 \\
\hline
\end{tabular}

Non-users $x \quad x \quad x$

$x \quad x \quad x \quad x \quad x$

$\begin{array}{llll}x & x & X\end{array}$

$\mathrm{x} \quad \mathrm{x}$

${ }^{\mathrm{a}} \mathrm{SB}$ : Single-bounded dichotomous choice; DC: Double-bounded dichotomous choice; PC: Payment card; OE: Open-ended WTP question 
Table 5. Methodological variables and sample characteristics included in the meta-analysis

\begin{tabular}{|c|c|c|}
\hline Variable & Description & Coding of variables \\
\hline Medium change & $\begin{array}{l}\text { Variable describing the medium impact of a valued } \\
\text { externality }\end{array}$ & $\begin{array}{l}\text { Dummy: 1=Medium change valued; } \\
0=\text { Small or large change valued }\end{array}$ \\
\hline Large change & $\begin{array}{l}\text { Variable describing the large impact of a valued } \\
\text { externality }\end{array}$ & $\begin{array}{l}\text { Dummy: } 1=\text { Large change valued; } \\
0=\text { Small or medium change valued }\end{array}$ \\
\hline Valuation method & Describes the valuation method applied & Dummy: $1=\mathrm{CE} ; 0=\mathrm{CV}$ \\
\hline Geographical location & Continent of survey implementation & Dummy: 1=Europe; 0=Other \\
\hline Offshore & $\begin{array}{l}\text { Describes whether the effects valued in the survey } \\
\text { are due to offshore or onshore wind power plants }\end{array}$ & $\begin{array}{l}\text { Dummy: } 1=\text { Offshore wind power } \\
\text { plants; } 0=\text { Onshore wind power } \\
\text { plants and studies that do not dis- } \\
\text { tinguish between the two categories }\end{array}$ \\
\hline Wind share & $\begin{array}{l}\text { Share of wind power in national electricity produc- } \\
\text { tion }\end{array}$ & Continuous variable (\%) \\
\hline Nuclear & $\begin{array}{l}\text { Describes whether the baseline scenario in the } \\
\text { survey includes nuclear power as an energy source }\end{array}$ & $\begin{array}{l}\text { Dummy: } 1=\text { Baseline scenario in- } \\
\text { cludes nuclear power; } 0=\text { Does not } \\
\text { include nuclear power }\end{array}$ \\
\hline Local residents & $\begin{array}{l}\text { Describes whether survey respondents live in close } \\
\text { vicinity of the planned wind power facilities }\end{array}$ & $\begin{array}{l}\text { Dummy: 1=Local residents; 0=Non- } \\
\text { residents }\end{array}$ \\
\hline Visitors & $\begin{array}{l}\text { Describes whether survey respondents are visitors } \\
\text { to the surrounding area of the planned wind power } \\
\text { facilities }\end{array}$ & Dummy: 1=Visitors; 0=Non-visitors \\
\hline Income & $\begin{array}{l}\text { Natural logarithm of median disposable household } \\
\text { income of survey participants or country where } \\
\text { survey was conducted in } 2014 \text { USD (adjusted for } \\
\text { GDP purchasing power parities and annual con- } \\
\text { sumer price inflation) }\end{array}$ & Continuous variable \\
\hline Year of study & Year of survey implementation & Continuous variable (0-14) \\
\hline
\end{tabular}


Table 6. Descriptive statistics of explanatory variables

\begin{tabular}{|c|c|c|c|c|c|c|c|}
\hline \multirow[b]{2}{*}{ Size of change } & \multirow[t]{2}{*}{$\begin{array}{l}\text { Mean WTP } \\
\text { (2014 USD) }\end{array}$} & \multirow[t]{2}{*}{ Std.Err. } & \multirow[t]{2}{*}{$\begin{array}{c}\text { Min. } \\
\text { value }\end{array}$} & \multirow[t]{2}{*}{$\begin{array}{l}\text { Max. } \\
\text { value }\end{array}$} & \multirow[t]{2}{*}{$\mathrm{N}^{\mathrm{a}}$} & \multicolumn{2}{|c|}{$\begin{array}{l}\text { Kruskal-Wallis } \\
\text { test statistic }\end{array}$} \\
\hline & & & & & & $\chi^{2}=7.926$ & $p=0.019$ \\
\hline Small change & 115.66 & 62.25 & 4.53 & 222.60 & 15 & & \\
\hline Medium change & 193.82 & 158.37 & 3.90 & 672.32 & 23 & & \\
\hline Large change & 294.80 & 242.82 & 35.21 & 905.49 & 14 & & \\
\hline Continents & & & & & & $\chi^{2}=8.135$ & $p=0.017$ \\
\hline Europe & 138.70 & 94.73 & 3.90 & 380.21 & 31 & & \\
\hline North-America & 329.23 & 253.34 & 66.99 & 905.49 & 15 & & \\
\hline Asia & 180.33 & 117.31 & 35.21 & 312.77 & 6 & & \\
\hline Valuation method & & & & & & $\chi^{2}=4.808$ & $p=0.028$ \\
\hline Choice Experiment & 235.44 & 201.40 & 4.53 & 905.49 & 34 & & \\
\hline Contingent Valuation & 128.62 & 88.43 & 3.90 & 330.10 & 18 & & \\
\hline Offshore/onshore & & & & & & $\chi^{2}=2.970$ & $p=0.227$ \\
\hline Offshore & 261.69 & 272.29 & 27.03 & 905.49 & 17 & & \\
\hline Onshore & 148.47 & 88.19 & 3.90 & 330.10 & 24 & & \\
\hline Not distinguished & 209.83 & 105.48 & 4.53 & 380.21 & 11 & & \\
\hline Visitors/local residents & & & & & & $\chi^{2}=0.829$ & $p=0.661$ \\
\hline Visitors & 175.35 & 171.30 & 31.63 & 542.29 & 7 & & \\
\hline Local residents & 209.97 & 215.26 & 3.90 & 905.49 & 20 & & \\
\hline Non-users & 195.72 & 150.38 & 4.53 & 704.66 & 25 & & \\
\hline
\end{tabular}

${ }^{\mathrm{a}}$ Number of observations. 
Table 7. Meta-analysis regression models

\begin{tabular}{|c|c|c|c|c|c|c|}
\hline \multirow[b]{2}{*}{ Variables } & \multicolumn{2}{|l|}{$\begin{array}{l}\text { Model 1: } \\
\text { WLS }^{\mathrm{a}}\end{array}$} & \multicolumn{2}{|c|}{$\begin{array}{l}\text { Model 2: } \\
\text { Random-effects }\end{array}$} & \multicolumn{2}{|c|}{$\begin{array}{l}\text { Model 3: } \\
\text { Mixed-effects }\end{array}$} \\
\hline & Coeff. & (s.e.) & Coeff. & (s.e.) & Coeff. & (s.e.) \\
\hline Constant & $-5.817^{*}$ & $(3.161)$ & -2.395 & $(3.892)$ & -2.545 & $(3.325)$ \\
\hline \multicolumn{7}{|l|}{ Type of externality } \\
\hline Air Pollution and climate change (improvement) & -0.297 & $(0.565)$ & -0.347 & $(0.289)$ & -0.533 & $(0.442)$ \\
\hline Biodiversity (improvement) & 0.500 & $(0.638)$ & 0.067 & $(0.416)$ & -0.256 & $(0.249)$ \\
\hline Biodiversity (deterioration) & -0.319 & $(0.449)$ & 0.562 & $(0.547)$ & 0.410 & $(0.404)$ \\
\hline Visual effects (improvement) & 0.334 & $(0.465)$ & $0.455^{*}$ & $(0.237)$ & $0.630^{\star \star \star *}$ & $(0.179)$ \\
\hline Visual effect (deterioration) & -0.155 & $(0.461)$ & $-0.584^{\star *}$ & $(0.283)$ & $-0.457^{\star \star}$ & $(0.209)$ \\
\hline Green Policy (improvement) & 0.309 & $(0.342)$ & $0.428^{\star *}$ & $(0.191)$ & $0.606^{\star \star \star}$ & $(0.110)$ \\
\hline \multicolumn{7}{|l|}{ Methodological and sample characteristics } \\
\hline Medium change valued & $1.033^{*}$ & $(0.522)$ & $0.872^{\star \star}$ & $(0.385)$ & $0.731^{\star \star \star}$ & $(0.191)$ \\
\hline Large change valued & $1.351^{\star * *}$ & $(0.484)$ & $1.221^{\text {** }}$ & $(0.346)$ & $1.218^{\star \star \star}$ & $(0.175)$ \\
\hline Valuation method $(1=\mathrm{CE}, 0=\mathrm{CV})$ & 0.533 & $(0.517)$ & 0.031 & $(0.468)$ & -0.070 & $(0.447)$ \\
\hline Europe & -0.314 & $(0.327)$ & -0.130 & $(0.308)$ & -0.375 & $(0.289)$ \\
\hline Offshore & -0.629 & $(0.544)$ & $-0.888^{\star *}$ & $(0.426)$ & $-1.157^{\star \star \star}$ & $(0.240)$ \\
\hline Share of wind power in national electricity production & 0.119 & $(0.094)$ & 0.155 & $(0.096)$ & $<0.001$ & $(0.060)$ \\
\hline (Share of wind power in national electricity production) $^{2}$ & $-0.012^{\star}$ & $(0.007)$ & $-0.015^{\star \star \star}$ & $(0.005)$ & -0.004 & $(0.005)$ \\
\hline Nuclear power included in the baseline scenario & 0.681 & $(0.465)$ & 0.078 & $(0.488)$ & 0.010 & $(0.517)$ \\
\hline Local residents & 0.309 & $(0.260)$ & 0.255 & $(0.445)$ & 0.335 & $(0.432)$ \\
\hline Visitors & 0.673 & $(0.625)$ & $1.167^{\star \star \star}$ & $(0.445)$ & $1.253^{\star \star \star}$ & $(0.198)$ \\
\hline Income (In) & $0.962^{\star \star \star}$ & $(0.268)$ & $0.706^{\star *}$ & $(0.345)$ & $0.738^{\star \star}$ & $(0.295)$ \\
\hline Year of study & -0.015 & $(0.037)$ & -0.042 & $(0.031)$ & -0.048 & $(0.031)$ \\
\hline \multicolumn{7}{|l|}{ Random-effects (group variable: studies) } \\
\hline$\sigma^{2}$ Air pollution and climate change (improvement) & - & - & - & - & 0.624 & $(0.441)$ \\
\hline$\sigma_{\text {Local residents }}^{2}$ & & & & & 0.377 & $(0.472)$ \\
\hline$\sigma_{\text {constant }}^{2}$ & - & - & $0.224^{*}$ & $(0.133)$ & $3.15 e-21$ & \\
\hline$\sigma_{\text {residual }}^{2}$ & - & - & $0.208^{\star \star \star}$ & $(0.084)$ & $0.108^{\star}$ & $(0.060)$ \\
\hline Log-likelihood & & & -47.433 & & -41.640 & \\
\hline AIC & & & 136.866 & & 127.278 & \\
\hline BIC & & & 177.843 & & 170.201 & \\
\hline
\end{tabular}


$\mathbf{R}^{2}$ (Pseudo- $\mathbf{R}^{2}$ )

Number of observations

52

52

52

${ }^{a}$ Weighted Least Squares $\mid{ }^{* \star \star} p<0.01,{ }^{\star \star} p<0.05,{ }^{*} p<0.1$ 


\section{Appendix}

Table A1. Interaction effects of scope with the valuation method

\begin{tabular}{|c|c|c|c|c|}
\hline \multirow[b]{2}{*}{ Variables } & \multicolumn{2}{|c|}{$\begin{array}{l}\text { Model 2: } \\
\text { Random-effects }\end{array}$} & \multicolumn{2}{|c|}{$\begin{array}{l}\text { Model 3: } \\
\text { Mixed-effects }\end{array}$} \\
\hline & Coeff. & (s.e.) & Coeff. & (s.e.) \\
\hline Constant & 0.028 & $(2.694)$ & -0.387 & $(3.088)$ \\
\hline \multicolumn{5}{|l|}{ Type of externality } \\
\hline Air Pollution and climate change (improvement) & -0.365 & $(0.293)$ & -0.354 & $(0.365)$ \\
\hline Biodiversity (improvement) & -0.036 & $(0.366)$ & -0.246 & $(0.283)$ \\
\hline Biodiversity (deterioration) & -0.016 & $(0.382)$ & 0.120 & $(0.393)$ \\
\hline Visual effects (improvement) & $0.413^{*}$ & $(0.214)$ & $0.443^{\star \star}$ & $(0.192)$ \\
\hline Visual effect (deterioration) & -0.448 & $(0.297)$ & -0.389 & $(0.239)$ \\
\hline Green Policy (improvement) & $0.933^{\star \star \star}$ & $(0.299)$ & $0.881^{\star \star \star}$ & $(0.204)$ \\
\hline \multicolumn{5}{|l|}{ Methodological and sample characteristics } \\
\hline Medium change valued & 0.159 & $(0.448)$ & 0.255 & $(0.476)$ \\
\hline Large change valued & -0.002 & $(0.530)$ & $0.731^{\star \star}$ & $(0.362)$ \\
\hline Medium change ${ }^{*}$ Choice experiment & $1.733^{\star \star \star}$ & $(0.514)$ & $1.215^{\star \star}$ & $(0.546)$ \\
\hline Large change * Choice Experiment & $2.504^{\star \star \star}$ & $(0.671)$ & $1.238^{\star *}$ & $(0.491)$ \\
\hline Valuation method $(1=\mathrm{CE}, 0=\mathrm{CV})$ & 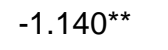 & $(0.517)$ & -0.723 & $(0.523)$ \\
\hline Europe & -0.323 & $(0.232)$ & $-0.419^{\star}$ & $(0.235)$ \\
\hline Offshore & $-1.185^{\star \star \star}$ & $(0.425)$ & 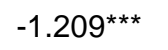 & $(0.275)$ \\
\hline Share of wind power in national electricity production & 0.107 & $(0.068)$ & 0.042 & $(0.053)$ \\
\hline (Share of wind power in national electricity production)^2 & $-0.012^{\star \star \star}$ & $(0.004)$ & $-0.006^{\star}$ & $(0.004)$ \\
\hline Nuclear power included in the baseline scenario & -0.018 & $(0.374)$ & 0.032 & $(0.442)$ \\
\hline Local residents & 0.325 & $(0.382)$ & 0.330 & $(0.407)$ \\
\hline Visitors & $1.747^{\star \star \star}$ & $(0.540)$ & $1.591^{\star \star \star}$ & $(0.337)$ \\
\hline Income (In) & $0.535^{\star \star}$ & $(0.246)$ & $0.558^{\star \star}$ & $(0.277)$ \\
\hline Year of study & $-0.056^{\star}$ & $(0.029)$ & $-0.057^{\star \star}$ & $(0.029)$ \\
\hline \multicolumn{5}{|l|}{ Random-effects (group variable: studies) } \\
\hline$\sigma_{\text {Air pollution and climate change (improvement) }}^{2}$ & - & - & 0.301 & $(0.524)$ \\
\hline$\sigma_{\text {Local residents }}^{2}$ & & & 0.333 & $(0.465)$ \\
\hline$\sigma_{\text {constant }}^{2}$ & $5.85 \mathrm{e}-17$ & $(4.73 e-15)$ & $1.65 \mathrm{e}-18$ & - \\
\hline$\sigma_{\text {residual }}^{2}$ & $0.289^{\star \star \star}$ & $(0.053)$ & 0.129 & $(0.098)$ \\
\hline Log-likelihood & -41.493 & & -39.672 & \\
\hline AIC & 128.986 & & 127.344 & \\
\hline BIC & 173.865 & & 174.174 & \\
\hline Pseudo- $R^{2}$ & 0.467 & & 0.490 & \\
\hline Number of observations & 52 & & 52 & \\
\hline
\end{tabular}

